\author{
UNIVERSIDADE DE SÃO PAULO \\ INSTITUTO DE FÍSICA DE SÃO CARLOS
}

Alexandre Benatti

Análise da evolução temporal do sinal nos detectores de superfície do Observatório Pierre Auger

São Carlos

2018 



\title{
Alexandre Benatti
}

\section{Análise da evolução temporal do sinal nos detectores de superfície do Observatório Pierre Auger}

\author{
Dissertação apresentada ao Programa de Pós- \\ Graduação em Física do Instituto de Física \\ de São Carlos da Universidade de São Paulo, \\ para obtenção do título de Mestre em Ciên- \\ cias. \\ Área de concentração: Física Básica \\ Orientador: Prof. Dr. Luiz Vitor de Souza \\ Filho

\section{Versão Corrigida} \\ (versão original disponível na Unidade que aloja o Programa)
}

\section{São Carlos}


AUTORIZO A REPRODUÇÃO E DIVULGAÇÃO TOTAL OU PARCIAL DESTE TRABALHO, POR QUALQUER MEIO CONVENCIONAL OU ELETRÔNICO PARA FINS DE ESTUDO E PESQUISA, DESDE QUE CITADA A FONTE.

Ficha catalográfica elaborada pelo Serviço de Biblioteca e Informação do IFSC, com os dados fornecidos pelo(a) autor(a)

Benatti, Alexandre
Análise da evolução temporal do sinal nos detectores de su-
perfície do Observatório Pierre Auger / Alexandre Benatti ;
orientador Luiz Vitor de Souza Filho - versão corrigida. - São
Carlos, 2018.
56 p.
Dissertação (Mestrado - Programa de Pós-Graduação em
Física Básica) - Instituto de Física de São Carlos, Universi-
dade de São Paulo, 2018.
1. Observatório Pierre Auger. 2. Chuveiros atmosféricos.
3. Detectores de superfície. 4. Reconhecimento de padrões. 5.
Sequências temporais. I. de Souza, Luiz Vitor, orient. II. Tí-
tulo.


Este trabalho é dedicado à minha família pelo apoio e incentivo oferecidos em todos os momentos de minha vida. 



\section{AGRADECIMENTOS}

Primeiramente, gostaria de agradecer aos meus pais Luiz Carlos e Tânia, pois sempre me apoiaram, me incentivaram e principalmente por serem meu exemplo de pessoa. Também quero agradecer ao meu irmão Fernando, por ser um amigo e um parceiro durante todos os momentos da vida.

Gostaria de agradecer também ao meu orientador prof. Dr. Vitor de Souza, um modelo de cientista, pelo qual tenho muita admiração e me sinto honrado por ter trabalho com ele durante esse período.

Além disso, meu agradecimento especial a todo o grupo de astrofísica do Instituto de Física de São Carlos. Durante esses dois anos, foi minha família e meu suporte. Pude compartilhar momentos inesquecíveis, tanto na parte profissional quanto pessoal. Dentre eles, agradeço Raul Prado que, com sua paciência, me ensinou muitas das ferramentas utilizadas neste trabalho. Agradeço ao Rodrigo Lang, por responder todos os meus questionamentos mais básicos. Agradeço ao Luan Arbeletche, que me ajudou com as ferramentas de simulação. E agradeço também aos meus amigos de sala: Victor Barbosa, companheiro durante o primeiro ano, e à Kaori Nakashima e Humberto Martinez, pela convivência durante o segundo ano.

Agradeço à Colaboração Pierre Auger pela oportunidade de trabalho, acredito que a experiência que eu obtive trabalhando em um experimento tão grande e importante foi essencial para o meu desenvolvimento como cientista. Agradeço o Laboratório Nacional de Computação Científica (LNCC) por fornecer os recursos do supercomputador SDumont, o qual contribuiu para os resultados encontrados neste trabalho. Agradeço também ao IFSC pela excelente estrutura fornecida, tanto material como de bons profissionais. Este foi um lar para a minha formação.

Finalmente, agradeço ao CNPq pelo apoio financeiro, por possibilitar o desenvolvimento deste trabalho. Nesta fase da vida, esse tipo de incentivo é essencial para a formação dos novos cientistas. 

"Deixem que o futuro diga a verdade e avalie cada um de acordo com o seu trabalho e realizações. $O$ presente pertence a eles, mas o futuro pelo qual eu sempre trabalhei pertence a mim." 



\section{RESUMO}

\section{BENATTI, A. Análise da evolução temporal do sinal nos detectores de}

superfície do Observatório Pierre Auger. 2018. 56p. Dissertação (Mestrado em Ciências) - Instituto de Física de São Carlos, Universidade de São Paulo, São Carlos, 2018.

Os detectores de superfície do observatório Pierre Auger são tanques repletos de água e completamente escuros com sensores fotomultiplicadores instalados na parte interna. Quando as partículas carregadas de chuveiros atmosféricos atravessam a água com velocidade acima a da luz nesse meio, geram radiação ultravioleta devido ao efeito Cherenkov. Os sensores fotomultiplicadores desses detectores medem e convertem essa radiação em sinais elétricos que são enviados para a central de dados, registrando assim um evento. Alguns eventos apresentam comportamento incomum, caracterizado por apresentar mais de uma estrutura na série temporal, coincidentes em pelo menos dois detectores de superfície distantes. Esse trabalho se dedicou a investigar sobre as características e origens desses eventos. Devido ao grande número de dados registrados pelo Observatório Pierre Auger, foi preciso desenvolver uma ferramenta computacional para reconhecer e selecionar aqueles eventos que apresentam as estruturas desejadas de forma automática. Após, esse filtro, tentamos determinar um padrão buscando semelhanças ou tendências em variáveis dos chuveiros, como a energia e a direção de chegada. Em segunda análise olhamos para os eventos híbridos, chuveiros observados pelos detectores de superfície e pelos telescópios de fluorescência simultaneamente, de modo a analisar o desenvolvimento longitudinal do chuveiro. Na sequência, foram realizado algumas simulações de chuveiros para alguns dos eventos selecionados com o algoritmo desenvolvido. Esses eventos foram então reconstituídos, simulando uma detecção pelo observatório, com o intuito de determinar se a origem desse sinal anômalo está relacionada a uma resposta dos detectores. O último passo, foi analisar a razão entre a proporção de eventos selecionados e o número total de eventos observados em função da energia da partícula primária, o que revelou uma relação entre essas duas grandezas.

Palavras-chave: Observatório Pierre Auger. Chuveiros atmosféricos. Detectores de superfície. Reconhecimento de padrões. Sequências temporais. 



\section{ABSTRACT}

BENATTI, A. Analysis of the temporal evolution of the signal in surface detectors of the Pierre Auger Observatory. 2018. 56p. Dissertação (Mestrado em Ciências) - Instituto de Física de São Carlos, Universidade de São Paulo, São Carlos, 2018.

The surface detectors of Pierre Auger observatory are water filled tanks and completely dark with photomultiplier sensors installed indoors. When charged particles of air showers cross the water with velocities above that of light in this medium, ultraviolet radiation is generated due to the Cherenkov effect. The photomultiplier sensors of these detectors measure and convert this radiation into electrical signals that are sent to the data center, thus recording an event. Some events have unusual behavior, characterized by having more than one structure in its time series, coincident in at least two distant surface detectors. This work was dedicated to investigate the characteristics and origins of these events. Due to the large amount of data recorded by the Pierre Auger Observatory it was necessary to develop a computational tool to automatically recognize and select those events that present the desired structure type. After applying this filter, we tried to determine a pattern by looking for similarities or trends in air-shower variables, such as energy and direction of arrival. In a second analysis, we looked at the hybrid events, air showers observed by the surface detectors and the fluorescence telescopes simultaneously, in order to analyze the longitudinal development of air shower. In the sequence, we performed some simulations of air showers for some events selected with the developed algorithm. These events were then reconstituted, simulating a detection by the observatory for the purpose of determinin if the origin of this anomalous signal is related to a response of the detectors. The last step was to analyze the ratio between the proportion of selected events and the total number of events observed as a function of the energy of the primary particle, which revealed a relation between these two quantities.

Keywords: Pierre Auger Observatory. Atmospheric air showers. Surface detectors. Patern recognition. Time series. 



\section{LISTA DE FIGURAS}

Figura 1 - Fluxo de raios cósmicos sobre a superfície da Terra em função da energia medido por diferentes experimentos. . . . . . . . . . . . .

Figura 2 - Esquema do desenvolvimento de um chuveiro atmosférico ao longo da atmosfera, destacando sua várias componentes. . . . . . . . . . . . 22

Figura 3 - Colaboração Pierre Auger. . . . . . . . . . . . . . . . . . . . . 25

Figura 4 - Esquema do Observatório Pierre Auger. Os SD são representados pelos pontos pretos e os FD são mostrados ao longo do perímetro da matriz dos detectores de superfície, onde as linhas indicam seu campo de visão. 26

Figura 5 - Principais componentes dos Telescópios de Fluorecência. . . . . . . . . 27

Figura 6 - Principais componentes dos Tanques Cherenkov. . . . . . . . . . . . 28

Figura 7 - Exemplo de sinal registrado pelos detectores de superfície no Observatório Pierre Auger. . . . . . . . . . . . . . . . . . . . . . . . . . . . . 31

Figura 8 - Exemplo de sinal anômalo e incomum observado em um dos detectores. 32

Figura 9 - Exemplo de evento anômalo detectado pelo Observatório. Em (a) é mostrado o sinal registrado por dois dos detectores SD, enquanto que (b) destaca quais tanques registraram o sinal e suas posições no observatório. 33

Figura 10 - Fluxograma do algoritmo do método para procurar picos. Os diferentes blocos emoldurados em linhas tracejadas são: leitura dos dados de entrada; procura pela posição e contagem dos picos; ajuste da curva sobre os dados; saída dos resultados. . . . . . . . . . . . . 35

Figura 11 - Contagem de estações em função do valor da razão sinal total pelo valor do pico máximo. . . . . . . . . . . . . . . . . . . . . . . 37

Figura 12 - Exemplo de eventos encontrados pelo algorítimo aplicado. . . . . . . . 39

Figura 13 - Histogramas de variáveis relacionadas às caraterísticas de chuveiros atmosféricos detectados pelo observatório. . . . . . . . . . . . . . . . . 42

Figura 14 - Histogramas de variáveis de direção dos chuveiros atmosféricos detectados pelo observatório. . . . . . . . . . . . . . . . . 43

Figura 15 - Perfil longitudinal (a) de um evento selecionado que apresenta um comportamento incomum, juntamente com a sequência temporal (b) e distribuição dos detectores de solo (c). Evento: auger_120227195300__sd_13621719 44

Figura 16 - Geometria do problema, destacando a distância percorrida ente os pontos de máximo de partículas e as estações no solo. . . . . . . . . . . 45

Figura 17 - Eventos escolhidos para serem simulados, destacando as características mais importantes - número do evento, energia e valor do zênite. . . . . 47

Figura 18 - Resumo dos resultados obtidos nas simulações de chuveiros atmosféricos. 48

Figura 19 - Porcentagem de eventos selecionados em função da energia. . . . . . . . 49 



\section{SUMÁRIO}

INTRODUÇÃO $\ldots \ldots \ldots \ldots \ldots \ldots \ldots$

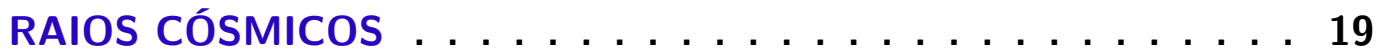

2.2 Chuveiros Atmosféricos . . . . . . . . . . . . . . 20

2.2 .1 Formação e Desenvolvimento . . . . . . . . . . . . . 20

$2.2 .2 \quad$ Componentes . . . . . . . . . . . . . . . . . . 22

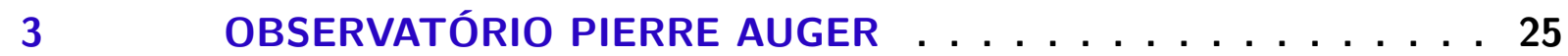

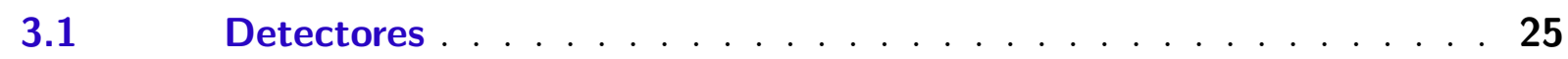

3.1.1 Telescópios de Fluorescência . . . . . . . . . . . . . . . . 27

3.1.2 Detectores de Superfície . . . . . . . . . . . . . . . . . . . . 28

3.2 Processamento de Dados . . . . . . . . . . . . . . . 29

3.2.1 Reconstrução de eventos . . . . . . . . . . . . . . . . . . . . . . . . . . 29

$3.2 .2 \quad$ Offline . . . . . . . . . . . . . . . . . . . 29

$3.3 \quad$ Principais Resultados do Observatório . . . . . . . . . . . . . 29

3.3.1 Espectro de energia de raios cósmicos ultra energéticos . . . . . . . . . 30

3.3.2 Anisotropia em larga escala nas direções de chegada dos raios cósmicos . . 30

3.3.3 Limites nos fluxos de fótons e neutrinos . . . . . . . . . . . . . 30

3.3.4 Estudos em interações hadrônicas . . . . . . . . . . . . . . 30

4 ANALISE TEMPORAL DO SINAL DOS DETECTORES DE SU-

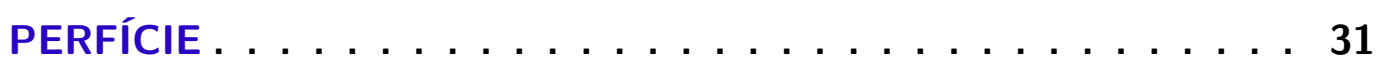

4.1 Análise qualitativa do sinal registrado pelos detectores de superfície 31

4.2 Análise quantitativa do sinal registrado pelos detectores de superfície 33

4.2.1 Algoritmo utilizado . . . . . . . . . . . . . . . . . . . 34

4.2.2 Seleção dos eventos . . . . . . . . . . . . . . . . . . . 36

$4.2 .3 \quad$ Exemplos de eventos identificados . . . . . . . . . . . . . 38

5 BUSCA POR PADRÕES EM EVENTOS . . . . . . . . 41

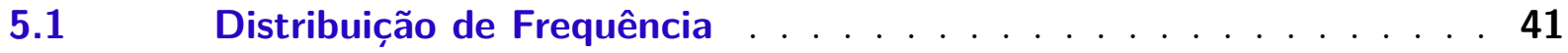

$5.2 \quad$ Análise do Desenvolvimento Longitudinal . . . . . . . . . . . . . 43

5.3 Procura por características incomuns em eventos simulados . . . . 46

5.4 Proporção de eventos selecionados frente ao total de eventos analisados . . . . . . . . . . . . . . . . 48 
REFERÊNCIAS .................... 53 


\section{INTRODUÇÃO}

A Terra é bombardeada constantemente por partículas produzidas em objetos astrofísicos as quais denominamos raios cósmicos. Essas partículas podem ser detectadas por instrumentos variados. Hoje sabemos que elas são produzidas em diversas regiões do Universo com um amplo espectro de energia e tipo. A radiação cósmica foi descoberta por volta de 1911 por especialistas em condutividade no ar. (1) Para investigar esse fenômeno, em 1912, Victor Franz Hess (2) realizou alguns experimentos por meio de balões carregando detectores de radiação. Hess concluiu, após as suas investigações, que a ionização observada era devida à ação de uma radiação desconhecida, altamente penetrante, provinda do espaço.

Desde sua descoberta, raios cósmicos se tornaram uma importante fonte de informação a respeito das partículas elementares e dos mecanismos astrofísicos mais extremos, representando assim uma conexão entre o micro e o macro da Natureza. Assim, várias partículas foram descobertas em estudos de raios cósmicos, por exemplo, Seth Neddermeyer e Carl Anderson (3) descobriram o pósitron em 1932, e em 1937 o múon. Ainda na década de 40, Pierre Victor Auger (4) fez uma descoberta fundamental para a evolução dos estudos em raios cósmicos. Ele mostrou que a interação da partícula cósmica com os núcleos da atmosfera gerava uma cascada de partículas que atingem a superfície terrestre em sincronia. Esse fenômeno ficou conhecido como chuveiro atmosférico e proporcionou um avanço significativo, pois possibilitou a detecção das partículas em detectores espalhados no chão, cobrindo a área coletora. Utilizando esta ideia, John Linsley (5) construiu um detector de chuveiros atmosféricos (Volcano Ranch) e em 1962 detectou raios cósmicos com energia inesperada. O evento medido por Linsley tinha energia da ordem de $10^{20} \mathrm{eV}$. No entanto, anos antes, Kenneth Greisen (6) e Georgi Zatsepin \& Vadem Kuzmin (7) propuseram que o limite superior para a energia dessas partículas deveria ser da ordem de $5 \times 10^{19} \mathrm{eV}$. Estava posto o enigma da geração de partículas de ultra alta energia cujos detalhes continuam por ser desvendados.

Dentro deste contexto, o Observatório Pierre Auger foi construído e vem produzindo importantes resultados. O Observatório será melhor descrito no Capítulo 3, porém, vale a pena ressaltar que ele é a maior instalação voltada para o estudo de raios cósmicos de altas energias, registrando da ordem de 33 mil eventos por ano com energia superior a $10^{18.4} \mathrm{eV}$. Constituído por duas técnicas de medida, detectores de superfície e telescópios de fluorescência, o Observatório faz uma medida híbrida de um conjunto de eventos com o objetivo de minimizar efeitos sistemáticos e garantir melhor resolução das medidas.

Esta dissertação se dedica ao estudo de dados do Observatório Pierre Auger, analisando a evolução temporal do sinal registrado nos detectores de superfície. Esses detectores possuem uma resolução temporal nunca antes utilizada em experimentos deste tipo (25 ns) 
e assim permitem estudar a evolução das partículas na frente do chuveiro atmosférico. A evolução temporal das partículas no chuveiro guarda importante informação sobre o tipo de partícula primária que iniciou o chuveiro atmosférico e também das interações ocorridas entre as partículas do chuveiro e os núcleos da atmosfera. Neste trabalho, caracterizaremos a evolução típica de chuveiros e buscaremos por sinais espúrios com estruturas temporais não bem definidas. Em particular, buscaremos estruturas coincidentes em detectores de superfície distantes, o que pode revelar subestruturas dos chuveiros relacionados com fragmentações da partícula primária. Utilizamos simulações de Monte Carlo dos chuveiros e detectores para qualificar o aparecimento dessas subestruturas e classificar seus tipos.

A origem dos raios cósmicos de altíssima energia (acima de $10^{18} \mathrm{eV}$ ) continua um mistério (8) depois de 60 anos da sua descoberta. A solução deste mistério levará à compreensão dos mecanismos mais extremos operando em objetos astrofísicos e pode também ajudar na descrição das interações elementares das partículas elementares. As respostas virão da operação continuada do Observatório Pierre Auger, de medidas de outros observatórios e de novos modelos inovadores. 


\section{RAIOS CÓSMICOS}

Esse capítulo traz uma introdução da física geral de raios cósmicos, Descrevendo suas principais características, origem no universo, espectro de energia e modelos de geração de chuveiros atmosféricos extensos. O texto é uma compilação de referências clássicas da área de física de partículas. (9-11)

\subsection{Origem}

Para citar alguns exemplos, os raios cósmicos podem ser prótons, núcleos de hélio, de oxigênio, de ferro ou até mesmo raios gamas, tendo origem em diferentes partes do universo e possuindo energia numa faixa que se estende de $10^{9}$ a $10^{21} \mathrm{eV}$.

Como são, em sua maioria partículas carregadas, seus caminhos podem ser alterados por qualquer campo magnético com o qual ele entre em contato. Como esses campos magnéticos estão presentes em todo o espaço, e aparecem em todas as direções, determinar suas fontes resultou ser uma difícil tarefa. (12)

No entanto, é muito provável que a produção dos raios cósmicos se origina de colisões entre a matéria interestelar, de remanescentes de explosões de supernovas, de núcleos ativos de galáxias, de estrelas de nêutrons, entre outros. (13)

A Figura 1 mostra o fluxo dessa radiação sobre a superfície da Terra em função de sua energia. Podemos observar que esse fluxo cai rapidamente com a energia, seguindo uma lei de potência $\left(\propto E^{-\gamma}\right)(14)$, sendo $\gamma$ denominado índice espectral. Porém o índice espectral muda para as várias faixas de energia (15-16):

- Sendo de $\gamma \sim 2,7$ até energias da ordem de $4 \times 10^{15} \mathrm{eV}$ (conhecido como joelho);

- Mudando para $\gamma \sim 3,0$ até energias próximas a $6 \times 10^{16} \mathrm{eV}$ (conhecido como segundo joelho);

- Sendo de $\gamma \sim 3,2$ na região que vai até $5 \times 10^{18} \mathrm{eV}$ (conhecido como tornozelo);

- Por fim, $\gamma \sim 2,53$ para energias mais altas. 


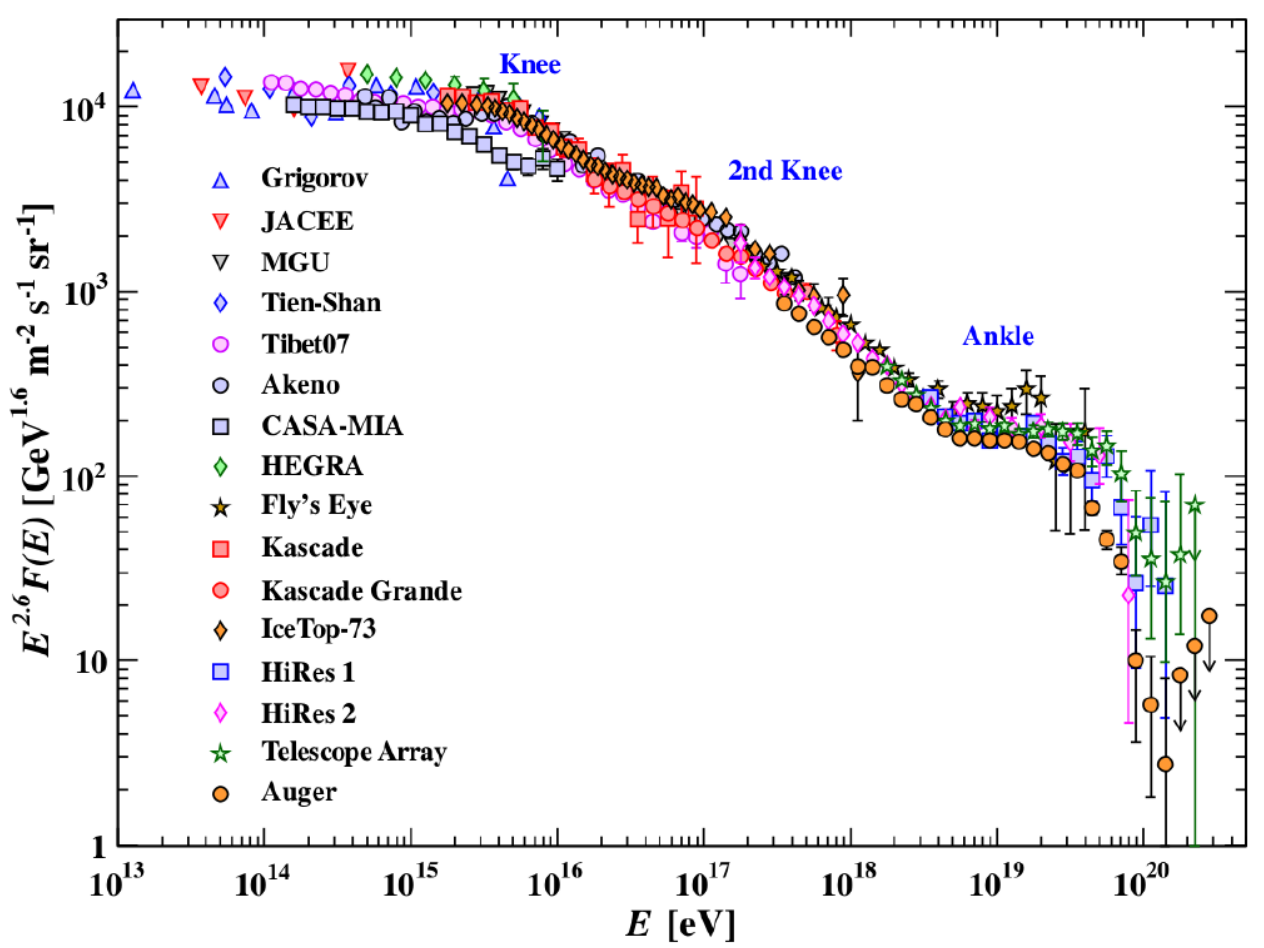

Figura 1 - Fluxo de raios cósmicos sobre a superfície da Terra em função da energia medido por diferentes experimentos.

Fonte: MOLLERACH; ROULET (17)

\subsection{Chuveiros Atmosféricos}

Raios cósmicos de energias menores que $1 \mathrm{TeV}$ são abundantes o suficiente para serem medidos por experimentos com área de detecção da ordem de $\mathrm{m}^{2}$. Assim, detectores dedicados são instalados em balões e na estação orbital para medir os raios cósmicos antes deles penetrarem na atmosfera terrestre.

Como partículas de alta energia são raras e é inviável levar grandes detectores ao espaço, sua detecção é feita de forma indireta, observando os chuveiros de partículas que são produzidos no ar utilizando detectores instalados no solo. Quando estas partículas entram na atmosfera, eventualmente colidem com moléculas presentes no ar e isso gera uma cascata de partículas secundárias que chamamos de chuveiro atmosférico extenso. (18)

\subsubsection{Formação e Desenvolvimento}

A colisão do raio cósmico com um núcleo da atmosfera gera uma quantidade imensa de partículas. Entre as mais abundantes estão os píons $\left(\pi^{+}, \pi^{0} e \pi^{-}\right)$e os káons $\left(\kappa^{+}, \kappa^{0} e \kappa^{-}\right)$. Píons e káons não são estáveis, portanto, podem decair em outras partículas. As partículas secundárias também podem colidir com outros núcleos, gerando outras 
cascatas secundárias, o que permite a continuidade do chuveiro.

O número de partículas começa a aumentar rapidamente à medida que este chuveiro ou cascata se desenvolve na atmosfera. Em cada interação, a energia do primário é dividida entre um número maior de partículas. Depois de algum ponto, o chuveiro atinge o máximo e o número de partículas do chuveiro diminui. Apenas uma pequena fração delas chega ao chão, o que vai depender da energia, do primário e da altitude da primeira interação.

Os telescópios de fluorescência medem o número de partículas do chuveiro em função da profundidade, o que chamamos de perfil longitudinal. O perfil de depósito de energia longitudinal é estimado por ajuste da Função de Gaisser-Hillas (19):

$$
f_{G H}(x)=\left(\frac{d E}{d x}\right)_{M A X}\left(\frac{x-x_{0}}{x_{M A X}-x_{0}}\right)^{\left(x_{M A X}-x_{0}\right) / \lambda} e^{\left(x_{M A X}-x_{0}\right) / \lambda} .
$$

As PMTs* das câmeras dos telescópios de fluorescência detectam os fótons gerados em consequência da fluorescência, do nitrogênio presente no ar, devido à passagem das partículas do chuveiro. Essa luz de fluorescência é emitida isotropicamente e na parte ultravioleta do espectro. Sendo $x_{0}$ e $\lambda$ parâmetros de ajustes e $x_{M A X}$ o ponto da atmosfera onde ocorre o máximo do número de partículas.

A função de distribuição lateral representa a quantidade de partículas em função da distância ao eixo do chuveiro. Os dados são obtidos a partir dos ajustes dos sinais das estações. Para descrever a distribuição lateral no solo é empregada a Função de Nishimura-Kamata-Greisen modificada (20):

$$
S(r)=S\left(r_{\text {opt }}\right)\left(\frac{r}{r_{\text {opt }}}\right)^{\beta}\left(\frac{r+r_{1}}{r_{\text {opt }}+r_{1}}\right)^{\beta+\gamma},
$$

onde $\beta$ e $\gamma$ são parâmetros de ajustes, $r_{o p t}$ é a distância ideal $\left(r_{o p t}=1000 \mathrm{~m}\right)$ e $r_{1}=700 \mathrm{~m}$.

A dependência do desenvolvimento do chuveiro com as características da atmosfera é um fator importante levado em consideração. As medidas do perfil são feitas geralmente em função da profundidade atmosférica, $X_{\nu}$, que esta relacionado ao perfil de densidade da atmosfera $\rho$ e a uma altitude $h$ pela equação:

$$
X_{\nu}=\int_{h}^{\infty} \rho\left(h^{\prime}\right) d h^{\prime}
$$

A profundidade atmosférica em que o chuveiro alcança o maior número de partículas é chamado de $X_{\max }$ que é um parâmetro muito importante para estudos de composição de raios cósmicos.

* Sigla em inglês para photomultiplier tube. 


\subsubsection{Componentes}

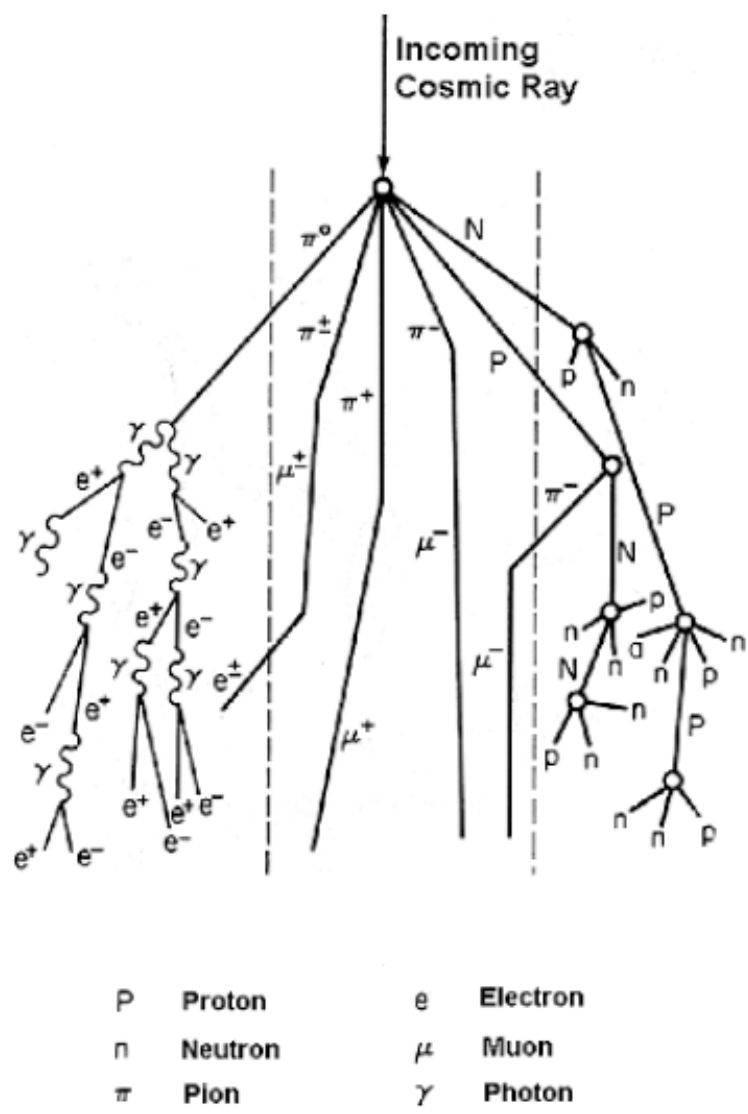

Figura 2 - Esquema do desenvolvimento de um chuveiro atmosférico ao longo da atmosfera, destacando sua várias componentes.

Fonte: HARNETT (21)

A Figura 2 mostra como esse chuveiro se desenvolve, destacando suas componentes: muônica, eletrônica e hadrônica.

\section{Componente Hadrônica}

A componente hadrônica é comumente formada por píons carregados ou káons provenientes de decaimentos, colisões ou ressonâncias de bárions. (22) Píons de energias mais baixas e káons decaem para formar a componente muônica.

Componente Muônica

Esta componente é gerada pelo decaimento dos píons e káons carregados em neutrinos $(\nu)$ e múons $\left(\mu^{+}\right.$e $\left.\mu^{-}\right)$. Devido ao fator da dilatação temporal eles têm um grande tempo de vida, portanto são capazes de atingir o solo. Múons com alta energia viajam aproximadamente em trajetória retilínea, porque sofrem um pequeno espalhamento, o que faz com cheguem mais rápido ao solo do que os elétrons. Devido a essas características, 
a componente muônica é muito útil na reconstrução das frentes do chuveiro no caso de detectores de superfície.

Os múons de energias mais elevadas detectados no solo são capazes de fornecer informação acerca dos processos ocorridos no desenvolvimento do chuveiro. Assim, eles podem ser usados para estudar a composição química do raio cósmico primário, porque sua multiplicidade depende do número atômico da partícula primaria.

Componente Eletromagnética

A componente eletromagnética é um processo dominante no desenvolvimento de chuveiros atmosféricos extensos. Ela é iniciada principalmente pelos fótons $(\gamma)$ gerados pelos decaimentos dos píons neutros. Estes fótons geram elétrons $\left(e^{-}\right)$e pósitrons $\left(e^{+}\right)$ através da produção de pares, que então geram mais fótons através do processo chamado de bremsstrahlung. Estes processos são repetidos iterativamente, gerando uma cascata de pares elétron-pósitron e fótons que continuarão até que a energia dos elétrons secundários atinja um nível crítico, onde a perda de ionização é igual à de bremsstrahlung. A cascata eletromagnética dissipa da ordem de $90 \%$ da energia da partícula primaria, tornando o número total de partículas eletromagnéticas proporcional a energia do chuveiro. (23) 



\section{OBSERVATÓRIO PIERRE AUGER}

O Observatório Pierre Auger (24-26) recebeu esse nome em homenagem ao físico que descobriu os chuveiros atmosféricos extensos. Foi idealizado em 1995 para estudar os raios cósmicos de energia mais alta com estatísticas e precisões sem precedentes. Sua construção ocorreu entre os anos de 2002 e 2008, porém comemorou seus primeiros resultados já em 2004 .

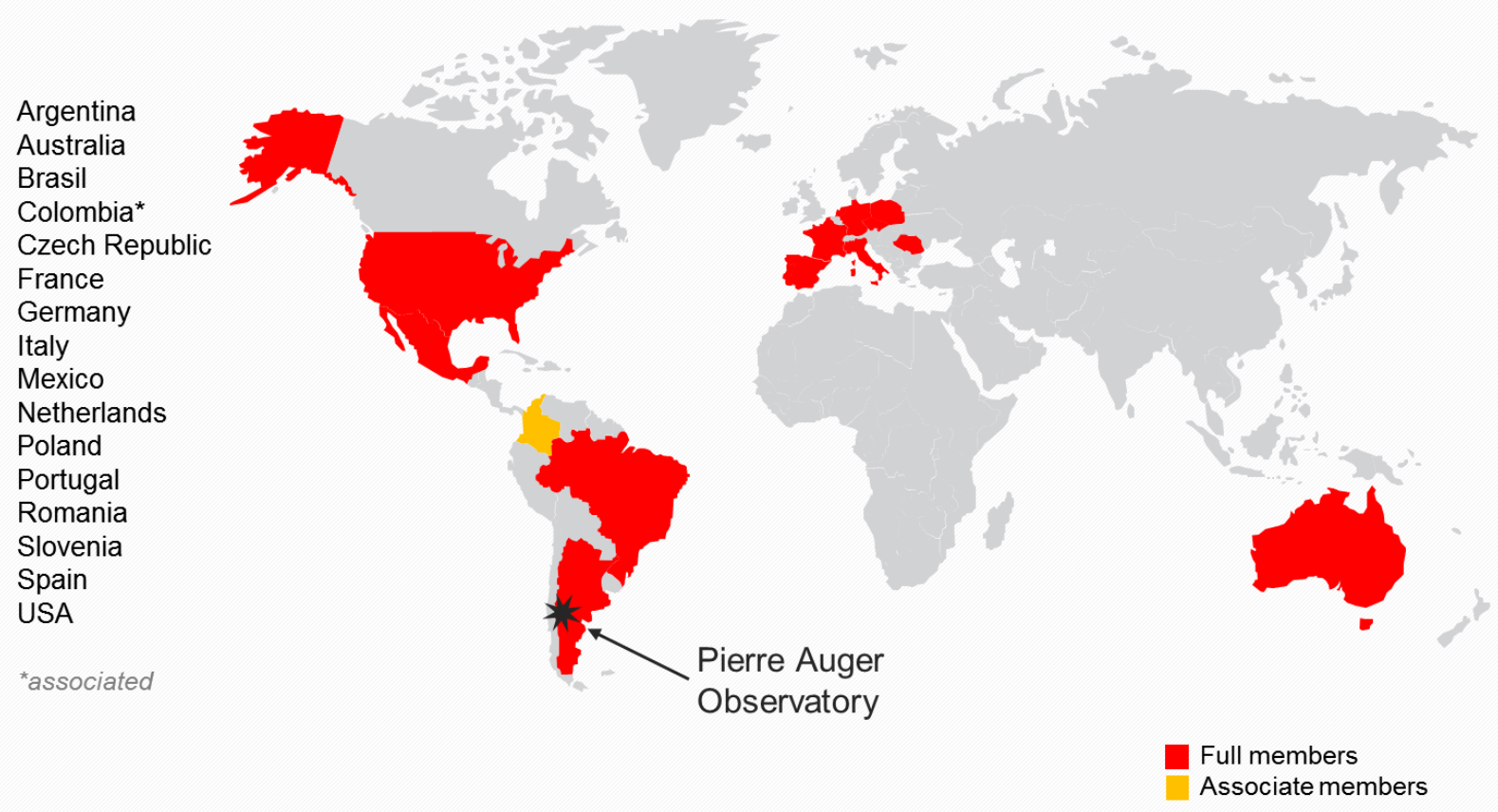

Figura 3 - Colaboração Pierre Auger.

Fonte: AUGER... (27)

A Figura 3 mostra os países membros da colaboração Pierre Auger, incluindo sua localização na Argentina, mais especificadamente próximo à cidade de Malargüe. Devido a sua importância, é considerado hoje a maior instalação voltada para o estudo de raios cósmicos de alta energia.

\subsection{Detectores}

A cascata de partículas e a luz produzida na atmosfera podem ser detectadas com uma matriz de detectores de superfície e telescópios ópticos. Os detectores de superfície usam detectores Cherenkov ou contadores de cintilação para detectar as partículas secun- 
dárias carregadas ao nível do solo. Já os telescópios são usados para medir a fluorescência e a luz Cherenkov através de grandes espelhos que focam essa luz em um conjunto de PMTs.

O observatório Auger se destaca por ser um detector hibrido, pois emprega dois métodos independentes: os detectores de fluorescência (FD, em inglês) e os detectores de superfície (SD, em inglês). Uma característica essencial deste projeto híbrido é a capacidade de observar os chuveiros simultaneamente por duas técnicas diferentes e complementares.

O objetivo é usar o FD e o SD para medir as mesmas propriedades dos raios cósmicos primários (energia, composição da massa e direção), mas fazê-lo usando diferentes técnicas com incertezas sistemáticas muito diferentes.

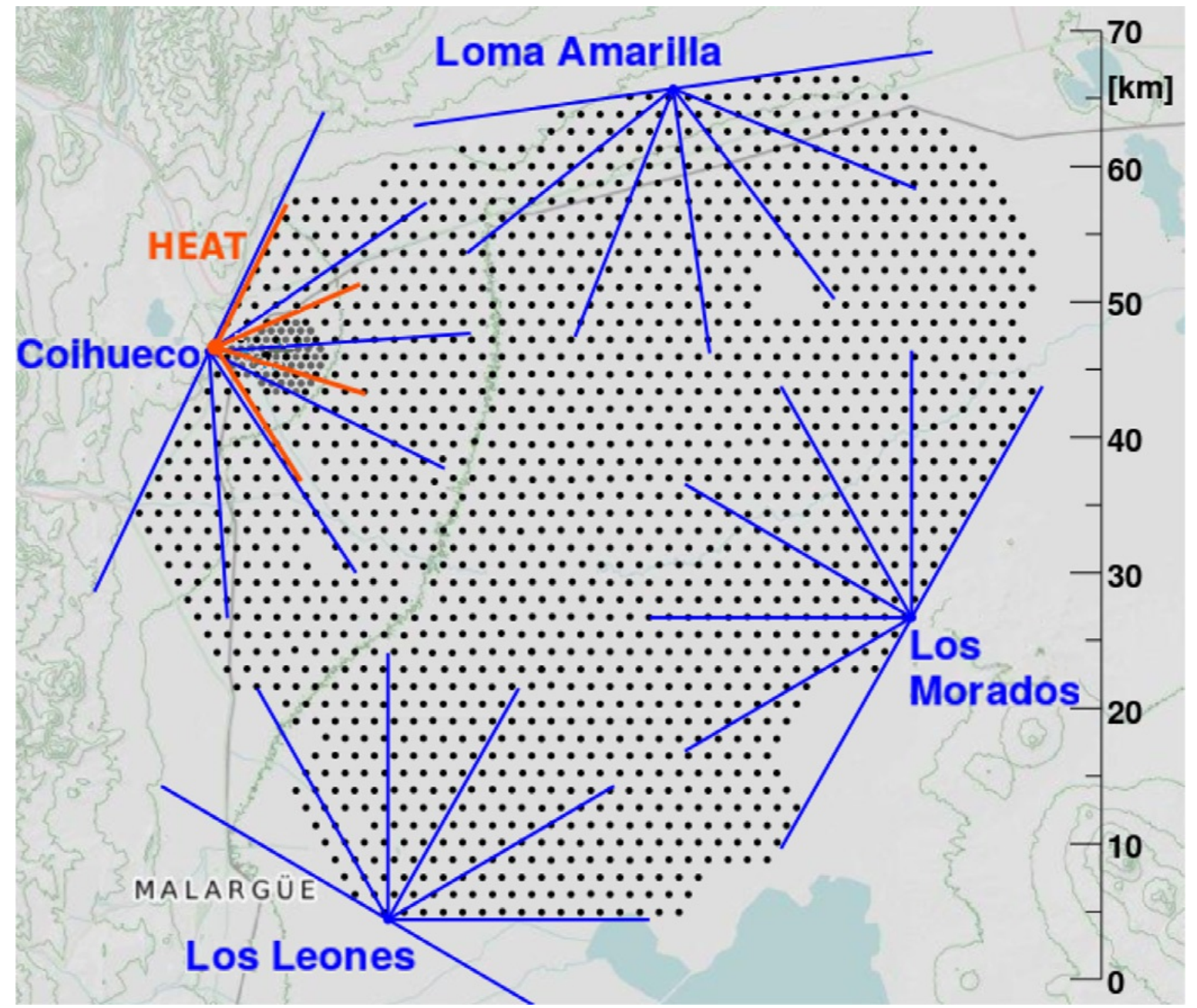

Figura 4 - Esquema do Observatório Pierre Auger. Os SD são representados pelos pontos pretos e os FD são mostrados ao longo do perímetro da matriz dos detectores de superfície, onde as linhas indicam seu campo de visão. 


\subsubsection{Telescópios de Fluorescência}

Os detectores FD foram projetados para medir a fluorescência do nitrogênio presente no ar, devido à passagem das partículas secundárias. Essa informação permite traçar o perfil longitudinal do chuveiro.

A luz de fluorescência é emitida de forma isotrópica na parte ultravioleta do espectro $(\sim 300-430 \mathrm{~nm})$ e é produzida predominantemente pela componente eletromagnética do chuveiro.

O FD é composto por 27 telescópios voltados para a matriz SD divididos em quatro sítios. Estes telescópios estão alojados em edifícios protegidos do clima, de poeira e da luz do dia. Os prédios dos quatro locais possuem seis telescópios independentes, e cada telescópio tem um campo de visão de $30^{\circ} \times 30^{\circ}$, levando a uma cobertura de $180^{\circ} \mathrm{em}$ azimute e de $2^{\circ}$ a $32^{\circ}$ em elevação. Existem também três telescópios denominados HEAT em elevações maiores, de $32^{\circ}$ a $62^{\circ}$, para registrar chuveiros de energias inferiores.

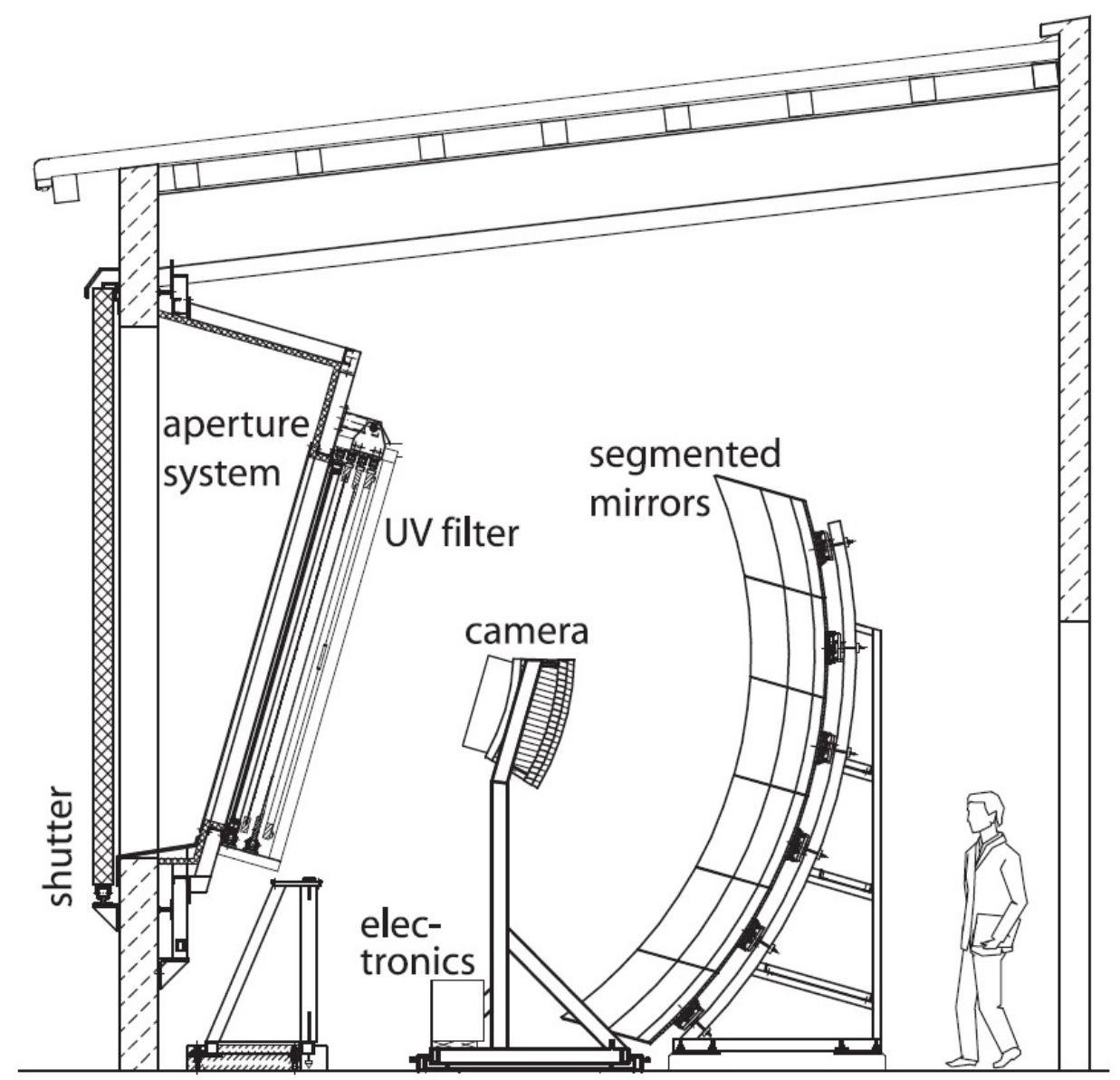

Figura 5 - Principais componentes dos Telescópios de Fluorecência.

Fonte: THE PIERRE AUGER COLLABORATION (25)

Os períodos de observação são limitados a noites escuras de bom tempo, represen- 
tando um ciclo de trabalho de $15 \%$ no momento atual. Esta desvantagem é compensada pelo considerável ganho de poder visualizar o desenvolvimento do perfil do chuveiro.

\subsubsection{Detectores de Superfície}

A estrutura terrestre do observatório Auger ocupa uma área de $3.000 \mathrm{~km}^{2}$, onde está instalado um total de 1.600 detectores de superfície, formando um arranjo triangular com uma separação de 1500 m entre cada detector.

Também chamadas de estações SD ou tanques Cherenkov, são tanques contendo 12 mil litros de água com alto grau de pureza, medindo 3,6 m de diâmetro e 1,6 m de altura.

A Figura 6 mostra os componentes presentes em cada SD.

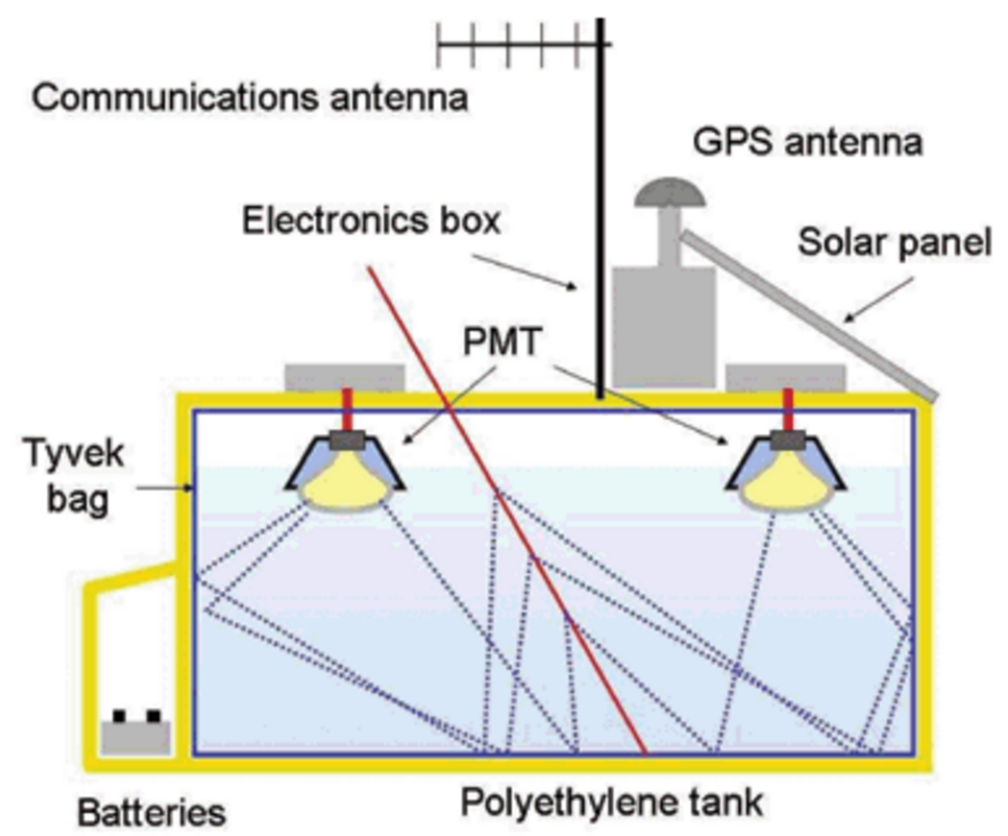

Figura 6 - Principais componentes dos Tanques Cherenkov.

Fonte: SHELLARD (28)

As partículas que chegam ao solo são detectadas quando atravessam o tanque e emitem radiação Cherenkov (29[p. 12]) pelo fato de sua velocidade ser maior que a da luz na água. Essa radiação é medida por sensores fotomultiplicadores e convertida em sinal elétrico.

O objetivo dos detectores de superfície é medir a função de distribuição lateral. 


\subsection{Processamento de Dados}

\subsubsection{Reconstrução de eventos}

A reconstrução da energia e a direção de chegada dos chuveiros atmosféricos produzidos pelos raios cósmicos se baseia na intensidade e tempo de chegada dos sinais registrados nas estações SD. Com esses dados, pode-se determinar a geometria do chuveiro, isto é, a direção do raio cósmico incidente e o tamanho do chuveiro.

Já a reconstrução híbrida é baseada em dados do detector de fluorescência com informações de temporização adicionais do detector de superfície. A medição FD da energia é usada para calibrar a escala de energia SD usando eventos observados por ambos os detectores, o que resulta em incertezas sistemáticas menores.

\subsubsection{Offline}

O software Offline $(30$ - 31) do Observatório Pierre Auger fornece uma infraestrutura de algoritmos para apoiar o desenvolvimento de simulações, reconstruções e análises. Essa estrutura é implementada em $\mathrm{C}++$, e aproveita o design orientado a objetos e as ferramentas comuns de código aberto, mantendo o lado do usuário simples.

Sua organização geral é uma coleção de módulos de processamento, montada e sequenciada através de instruções contidas em um arquivo XML ou em um script Python. Este design modular permite aos colaboradores trocar código, comparar algoritmos e criar uma variedade de aplicativos combinando módulos em várias sequências. As interfaces para informações de detectores e eventos libertam os usuários de ter que lidar individualmente com vários formatos e fontes de dados.

Este software fornece mecanismos para facilitar o desenvolvimento colaborativo de algoritmos para abordar várias tarefas de análise, bem como ferramentas para auxiliar na configuração e na contabilidade necessárias para a produção de dados simulados e reais. A estrutura do Offline inclui duas hierarquias paralelas para acessar dados: a descrição do detector para recuperar dados das constantes de calibração e condições atmosféricas, incluindo geometria do detector e um modelo de dados de eventos para ler e escrever informações que mudam para cada evento.

O Offline, embora ainda estando em constante desenvolvimento e incluindo melhorias, tem sido importante na produção dos vários resultados físicos do observatório.

\subsection{Principais Resultados do Observatório}

Desde que o Observatório Pierre Auger toma dados, já realizou importantes descobertas e obteve grandes resultados em física de partículas, consolidando-se como uns dos principais experimentos na área e obtendo destaque no estudo de raios cósmicos de alta 
energia. Nessa seção são dados alguns exemplos de resultados obtidos.

3.3.1 Espectro de energia de raios cósmicos ultra energéticos

O Observatório Pierre Auger foi o primeiro experimento a medir com precisão o fluxo de raios cósmicos ultra energéticos (energia maior que $3 \times 10^{17} \mathrm{eV}$ ) após 10 anos em operação. (32) Estes dados são essenciais para entender a origem e os mecanismos de aceleração dos raios cósmicos. O espectro de energia acima de $3 \times 10^{17} \mathrm{eV}$ foi medido combinando três grupos diferentes de dados: SD-1500 m que usa dados da matriz de 1500 $\mathrm{m}$ e foi projetado para as mais altas energias, SD-750 m que usa dados da matriz de 750 $\mathrm{m}$ e é projetado para as energias mais baixas e eventos híbridos, eventos detectados tanto por SD quanto por FD.

\subsubsection{Anisotropia em larga escala nas direções de chegada dos raios cósmicos}

Usando da ordem de 30 mil eventos acima de $8 \times 10^{18} \mathrm{eV}$, registrados com o Observatório Pierre Auger, foi relatada uma anisotropia nas direções de chegada. (33) A anisotropia em larga escala pode revelar tanto os efeitos da distribuição global de fontes, quanto o movimento coletivo de raios cósmicos. (34) As indicações de possíveis regiões quentes nas direções de chegada para raios cósmicos com energia acima de $50 \mathrm{EeV}$ foram relatadas pelas colaborações Pierre Auger e Telescope Array (35) e comparando esses resultados com as previsões fenomenológicas, descobriu-se que a magnitude e a direção da anisotropia suportam a hipótese de uma origem extragaláctica para os raios cósmicos de maior energia, em vez de fontes dentro da Galáxia.

\subsubsection{Limites nos fluxos de fótons e neutrinos}

A procura por fótons e neutrinos com energia acima de $10^{18} \mathrm{eV}$ é importante para restringir os modelos relacionados à origem dessas partículas nessa faixa de energia, eliminando modelos teóricos de geração destas partículas. (36) Importantes buscas foram realizadas com o conjunto de dados do Observatório Pierre Auger, porém ainda nenhum evento iniciado por estas partículas foi encontrado.

\subsubsection{Estudos em interações hadrônicas}

Além das investigações astrofísicas em raios cósmicos ultra energéticos, o Observatório Pierre Auger também contribui para o estudo das interações de partículas, por operar em um domínio de energia inalcançável por qualquer acelerador terrestre. Com isso, pode testar os modelos de interação hadrônica derivados dos dados de aceleradores. Como exemplo desses estudos podem ser citados: A estimativa da secção de choque próton-ar (37) e a primeira medida híbrida do número médio de múons em chuveiros atmosféricos, iniciadas com ângulo zenital entre $62^{\circ}$ e $80^{\circ}$. (38) 


\section{ANALISE TEMPORAL DO SINAL DOS DETECTORES DE SUPERFÍCIE}

Quando as partículas atingem uma estação SD, um pequeno computador irá conferir por rádio com computadores em uma central de aquisição de dados para decidir se as partículas fazem parte de um grande chuveiro. Em caso afirmativo, informações sobre o chuveiro serão transmitidas para a central de dados. Os computadores dessa central combinarão as medidas do número de partículas e seu horário de chegada em cada estação para determinar a direção e a energia do raio cósmico original que provocou o chuveiro.

\subsection{Análise qualitativa do sinal registrado pelos detectores de superfície}

As informações coletadas pelos detectores e processadas pela central de dados são o número de múons, elétrons e fótons que atravessam o tanque. Esses detectores registram um espectro de uma frente de partículas utilizando fotomultiplicadoras com dispositivo FADC* em função do tempo. Os dados são amostrados em $\mathrm{VEM}^{\dagger}$ distribuídos em intervalos de 25 ns.

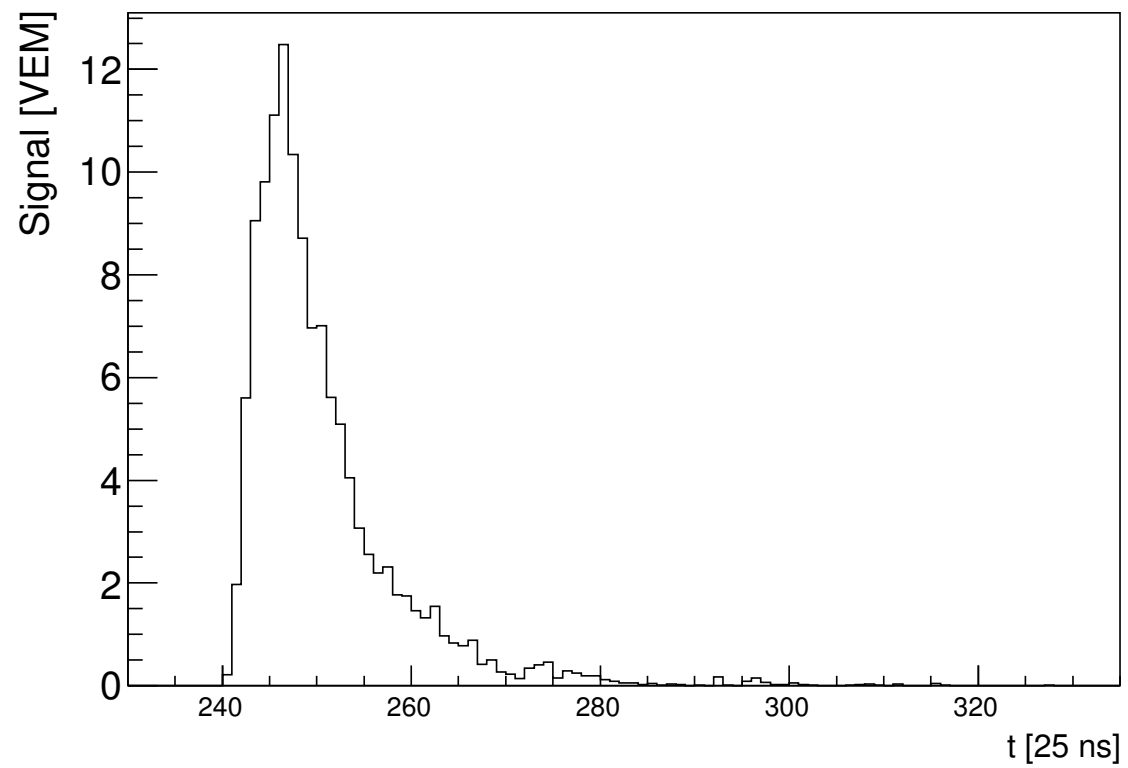

Figura 7 - Exemplo de sinal registrado pelos detectores de superfície no Observatório Pierre Auger.

Fonte: Elaborada pelo autor.

* Sigla em inglês para Fast Analog to Digital Converters

$\dagger$ Sigla em inglês para Vertical Equivalent Muon 
A Figura 7 mostra um exemplo de sinal típico desses detectores, onde é registrado o sinal deixado pelas partículas em função do tempo.

É possível notar um crescimento rápido, provocado pela frente de partículas do chuveiro composta principalmente por múons. Os múons possuem menor probabilidade de interação e chegam primeiro nos detectores. O lado direito do espectro contém um caimento mais lento do sinal, provocado pela componente eletromagnética do chuveiro que é composta de partículas que espalham mais na atmosfera e consequentemente chegam mais atrasadas ao solo.

Porém, em alguns eventos, certos detectores no solo mostram um comportamento distinto, apresentando uma sequência temporal incomum. Neles aparece múltiplos picos e sinais com uma largura maior.

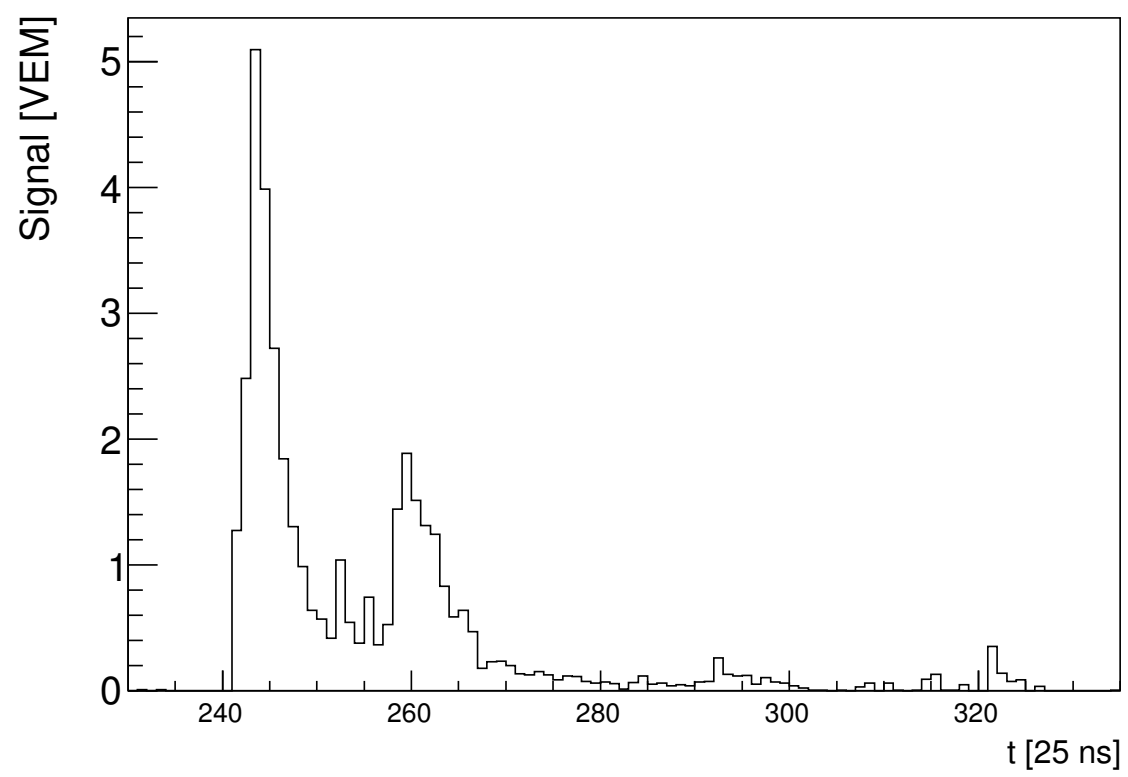

Figura 8 - Exemplo de sinal anômalo e incomum observado em um dos detectores.

Fonte: Elaborada pelo autor.

A Figura 8 mostra um exemplo com as características descritas anteriormente. Nela é possível notar a formação de uma segunda estrutura na sequência temporal, como se fosse criado um chuveiro secundário ao longo do seu desenvolvimento ou uma segunda frente de partículas. Neste trabalho, procuramos identificar e estudar essas estruturas temporais anômalas.

O sinal procurado se caracteriza por ter mais de um pico na evolução temporal, e além disso, que a forma do sinal seja coincidente em pelo menos dois detectores. Dessa forma, temos o sinal registrado simultaneamente por detectores que estão separados por 
pelo menos 1,5 km e ambos apresentam um comportamento incomum.

Essas condições garantem a observação de uma característica real do chuveiro e não uma flutuação local de partículas e também aponta para algo que ocorre em um ponto mais alto da atmosfera e não próximo ao solo.

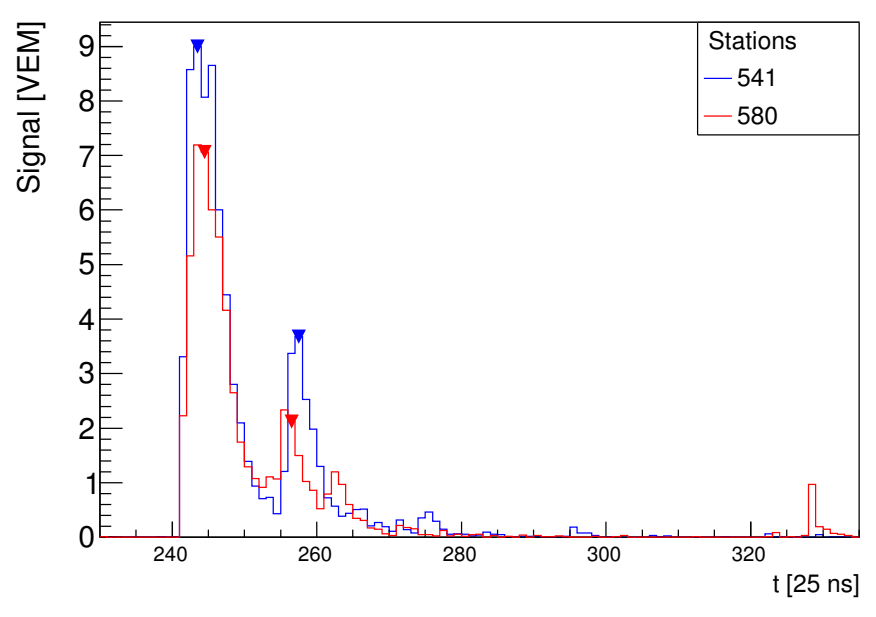

(a)

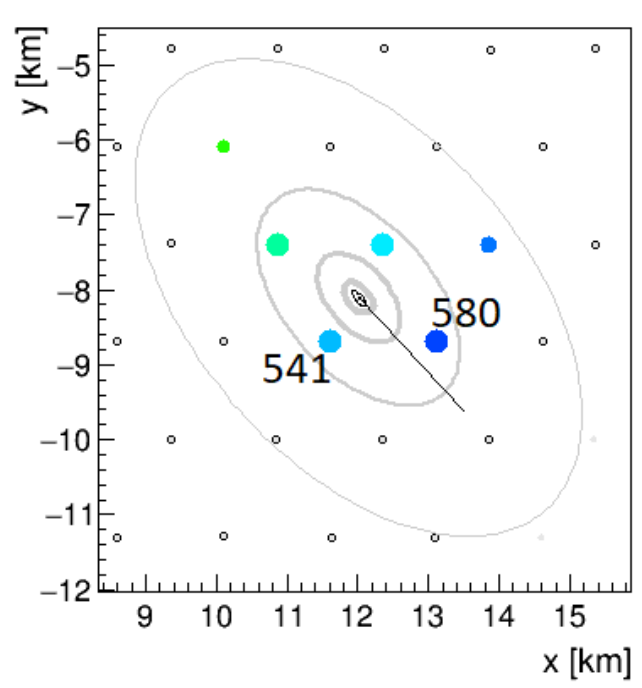

(b)

Figura 9 - Exemplo de evento anômalo detectado pelo Observatório. Em (a) é mostrado o sinal registrado por dois dos detectores $\mathrm{SD}$, enquanto que (b) destaca quais tanques registraram o sinal e suas posições no observatório.

Fonte: Elaborada pelo autor.

A Figura 9 traz um exemplo para ilustrar as características citadas. A imagem da direita mostra um chuveiro que chega ao solo e foi detectado pelas estações SD que estão coloridas. O gráfico, à esquerda, mostra a sequência temporal registrada por dois desses detectores que apresentam o sinal incomum e coincidente procurado.

A análise da evolução temporal desses detectores é interessante pelo fato de criar a possibilidade de entender melhor o comportamento dos chuveiros atmosféricos extensos e ainda poder encontrar e descrever um novo fenômeno até o momento desconhecido.

\subsection{Análise quantitativa do sinal registrado pelos detectores de superfície}

Os detectores de superfície do Observatório Pierre Auger operam 24 horas por dia, detectando uma grande quantidade de eventos. Para os estudos desse trabalho foram analisados os dados registrados entre julho de 2014 a dezembro de 2016, ou seja, dados de um período de dois anos e meio. 
Devido ao grande número de eventos a serem analisados, foi necessário utilizar uma ferramenta computacional para automatizar alguns processos.

Para isso, foi escrito um código em C++ e foram usadas algumas bibliotecas do ROOT (39), com o objetivo de criar um filtro capaz de identificar os eventos incomuns, separá-los do conjunto total de dados e montar os gráficos das sequências temporais das estações SD desejadas.

\subsubsection{Algoritmo utilizado}

A seguir será descrito o algoritmo aplicado para a separação dos dados analisados com o objetivo de ilustrar seu funcionamento e também demonstrar a metodologia aplicada.

Contagem de picos

Estão disponíveis na literatura várias ferramentas matemático-computacionais de análise de sequências temporais. Nesta dissertação, utilizamos uma das mais populares baseada em técnicas de deconvolução. Explicamos abaixo de forma resumida o argumento principal do algoritmo aplicado na análise.

Para determinar o número de picos nos sinais a serem analisados foi utilizado um algoritmo que encontra a posição e o número de picos em uma sequência temporal automaticamente. (40) O método permite utilizar o computador para procurar picos na presença de um fundo e flutuações estatísticas.

A metodologia se baseia em assumir que os picos podem ser descritos por funções contínuas, gaussianas e que o fundo pode ser aproximado por uma função linear, para intervalos curtos:

$$
N(x)=G(x)+B+C x
$$

onde $G(x)$ representa uma função gaussiana, $B$ e $C$ são constantes que descrevem um sinal de fundo. Dessa maneira, sua segunda derivada torna-se independente do plano de fundo e desaparece para qualquer intervalo em que não haja pico. Desse modo, um pico será localizado onde quer que $N^{\prime \prime}(x) \neq 0$.

$\mathrm{Na}$ prática, os dados representam uma função discreta no intervalo i,

$$
N_{i}=A \exp \left[\frac{-\left(i-i_{0}\right)^{2}}{2 \sigma^{2}}\right]+B+C x
$$

Devido à natureza discreta a segunda derivada é substituída pela segunda diferença da taxa de contagem como uma função do número do intervalo:

$$
S_{i}=N_{i+1}-2 N_{i}+N_{i-1}
$$

O computador realiza uma média nos pontos vizinhos dessa função para reduzir o efeito da flutuação estatística. 
No entanto, os valores de $S_{i}$ flutuam em torno do valor esperado de acordo com seu desvio padrão:

$$
F_{i}=\left[N_{i+1}+4 N_{i}+N_{i-1}\right]^{1 / 2}
$$

Assim, o algoritmo reconhece a presença de um pico quando um grupo de pontos que atinja pelo menos um desvio padrão acima de zero precede outro grupo de pontos negativos. Esta sequência pode ser correlacionada com a segunda derivada de uma função gaussiana.

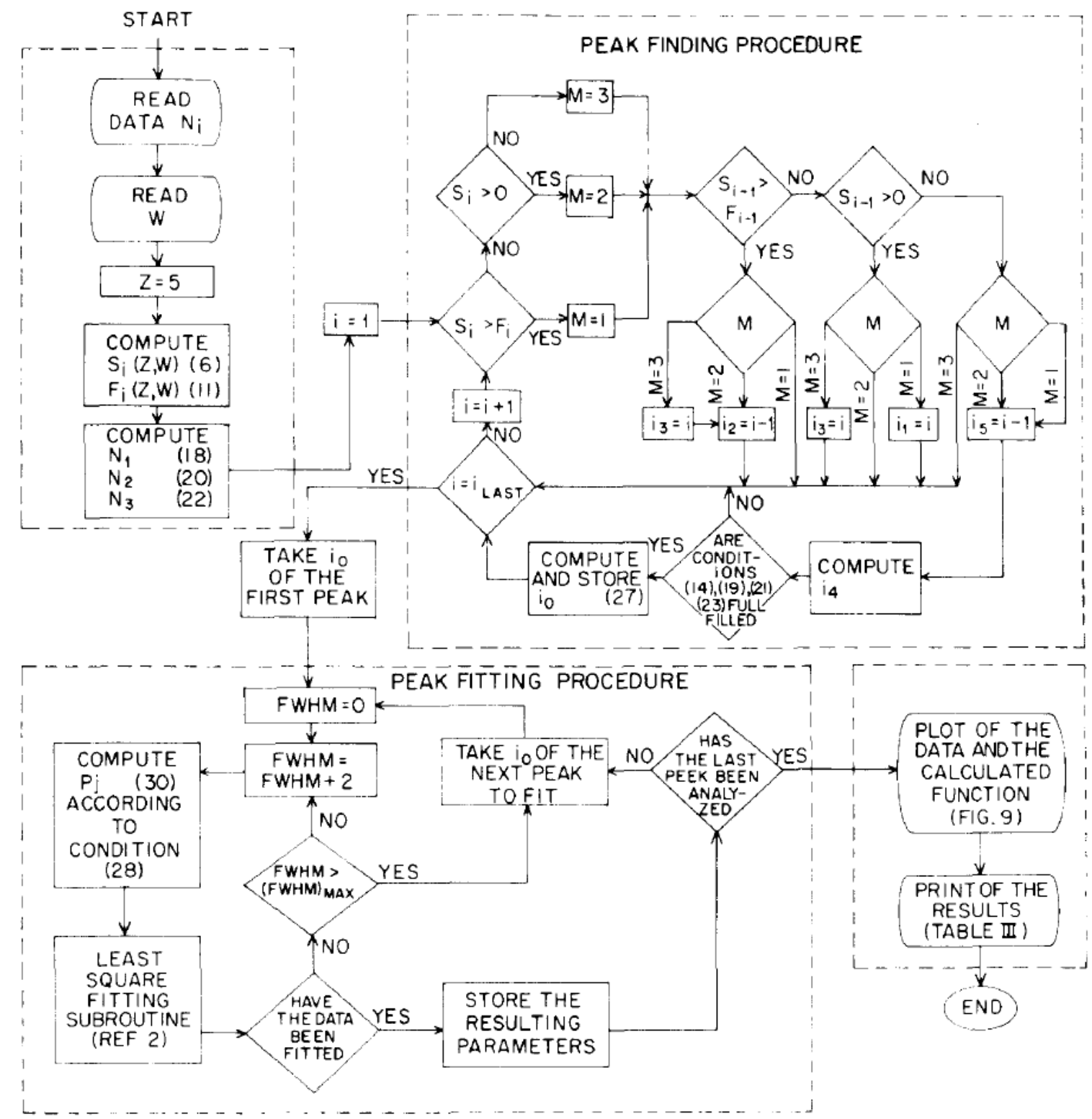

Figura 10 - Fluxograma do algoritmo do método para procurar picos. Os diferentes blocos emoldurados em linhas tracejadas são: leitura dos dados de entrada; procura pela posição e contagem dos picos; ajuste da curva sobre os dados; saída dos resultados.

Fonte: MARISCOTTI. (40) 
A Figura 10 mostra um fluxograma com os detalhes do algoritmo proposto para aplicar o método descrito, onde é dividido em quatro partes para um melhor entendimento. Na primeira ocorre a leitura do espectro a ser analisado. Na segunda é dedicada a encontrar os picos existentes de acordo com o método apresentado. A terceira parte determinar a função Gaussiana que melhor se adapta sobre os dados. Por último, a quarta parte é a saída do programa onde é listado a posição, amplitude e largura de cada pico encontrado.

O método descrito foi implementado por meio das ferramentas disponíveis na biblioteca ROOT, através a classe Tspectrum (<https://root.cern.ch/doc/master/classTSpectrum. html>) utilizando a função SearchHighRes. Essa função oferece aos usuários a possibilidade de variar os parâmetros de entrada para identificar automaticamente os picos no espectro com a presença de um fundo contínuo e flutuações estatísticas.

Correlação entre os picos

Outra característica importando do padrão procurado é o fato dos sinais entre estação do mesmo evento estarem correlacionados, ou seja, apresentarem o mesmo comportamento. Isso garante que as subestruturas detectadas chegaram aos detectores com a mesma diferença de tempo da frente de partículas, indicando que a origem dos dados medidos está relacionada ao mesmo fenômeno.

Para a seleção dos dados essa correlação foi determinada por meio da distância de cada pico com relação ao primeiro pico do espectro, adotado uma tolerância máxima de 3 bins, para mais ou para menos.

Portando, dois sinais foram considerados como correlacionados quando a distância do primeiro pico para os demais for igual no espectro medido por dois detectores, tomando como margem de erro \pm 3 bins.

\subsubsection{Seleção dos eventos}

No contexto de examinar muitos dados, nem todos são vantajosos ou aproveitáveis para uma análise efetiva. Sendo assim foi aplicado alguns filtros como o propósito de eliminar alguns eventos e estações indesejáveis.

Com a finalidade de selecionar apenas os melhores dados, foi adotado alguns parâmetros de seleção. O primeiro deles foi ignorado eventos com energia menor que $10^{18.4}$ eV, pois o observatório tem melhor sensibilidade para eventos de energias mais altas.

Também foi considerado apenas estações que possuíam o sinal de pelo menos 2 PMTs para a reconstrução do sinal, além de desconsiderar aquelas cuja soma do sinal era muito baixo, da mesma ordem dos níveis normais de ruído. Desse modo, só foi considerado como dados válidos aqueles com sinal total maior que 40 VEM e com pico máximo acima de 5 VEM. 
Por fim, foi adotado um último filtro para eliminar sinais muito ruidosos. Em vista disso, foi escolhido como parâmetro de seleção a razão: valor do sinal total pelo valor do pico máximo de cada estação. Para determinar qual valor de corte adotar foi utilizado um grupo de amostra ( $\approx 600$ estações), com sinais selecionados e classificados em dois grupos manualmente. Desejados (possuíam o padrão procurado) no primeiro grupo e indesejados (padrão normal e não deveriam ser selecionados) no segundo.

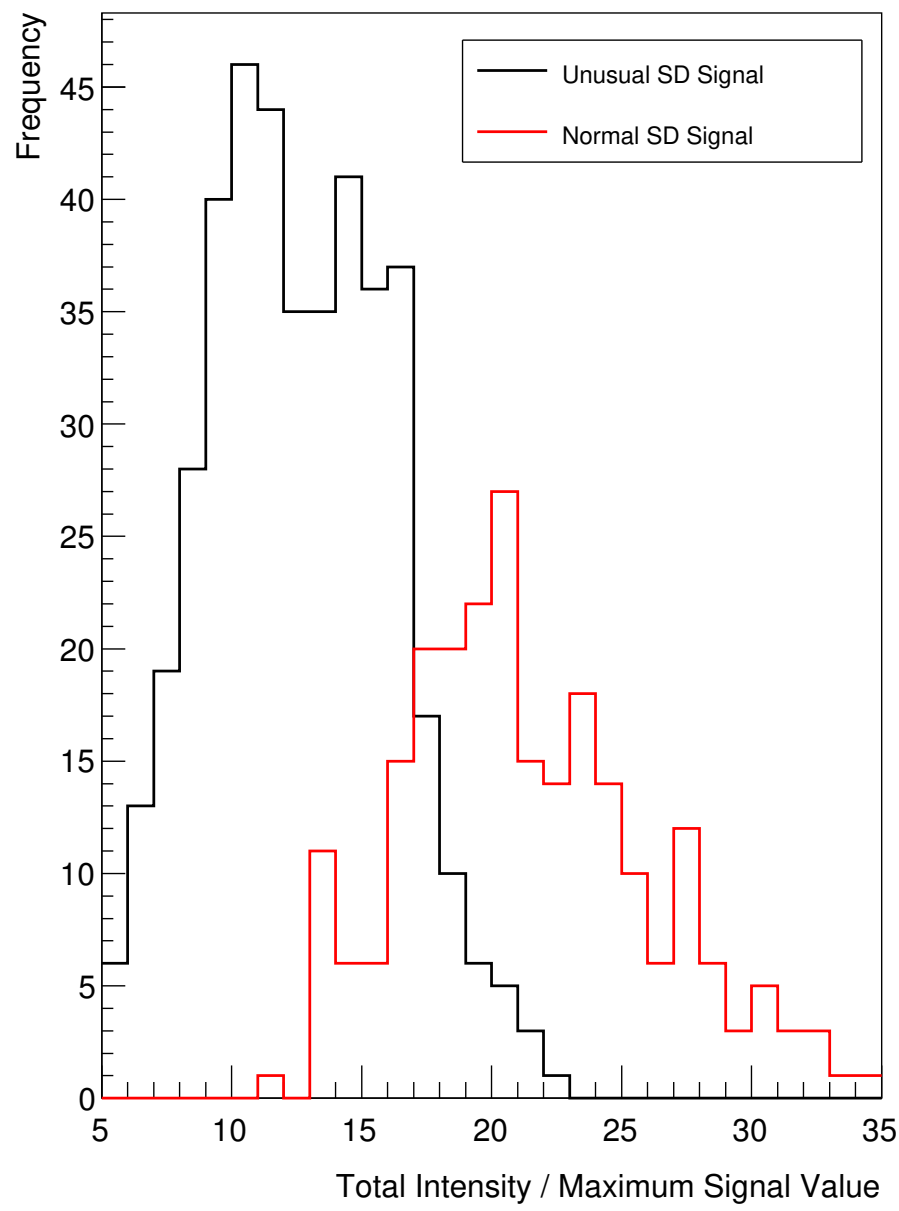

Figura 11 - Contagem de estações em função do valor da razão sinal total pelo valor do pico máximo.

Fonte: Elaborada pelo autor.

A Figura 11 mostra número de eventos encontrados em função da razão definida para os dois grupos mencionados.

Em preto, temos os sinais incomuns desejados e em vermelho os sinais comuns que devem ser desconsiderados. Como parâmetro de corte foi determinado, a partir do gráfico, que seriam apenas considerados os sinais com o valor da razão menor que 17. Essa escolha 
foi determinada escolhendo o ponto em que as duas curvas se interceptam, de forma a minimizar o erro de seleção.

\subsubsection{Exemplos de eventos identificados}

Para ilustrar o desempenho do algoritmo aplicado e mostrar os resultados obtidos com ele, foram separados alguns dos eventos encontrados aplicando o método descrito, para serem utilizados como exemplo. Cada gráfico exibe todas as estações que apresentam o comportamento procurado no mesmo evento, destacando com marcadores as posições dos picos encontrados.

Evento: auger_160925809500__sd_37427854

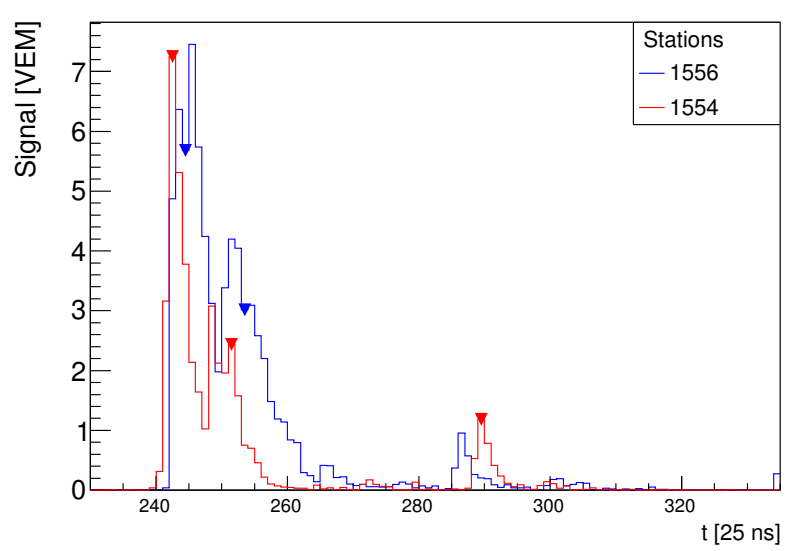

Evento: auger_152051641500__sd_33936806

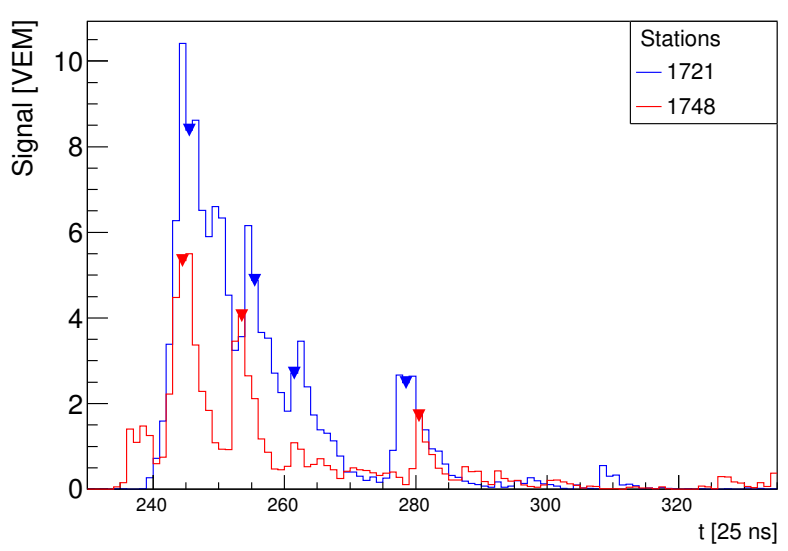

Evento: auger_143508225200__sd_30606474

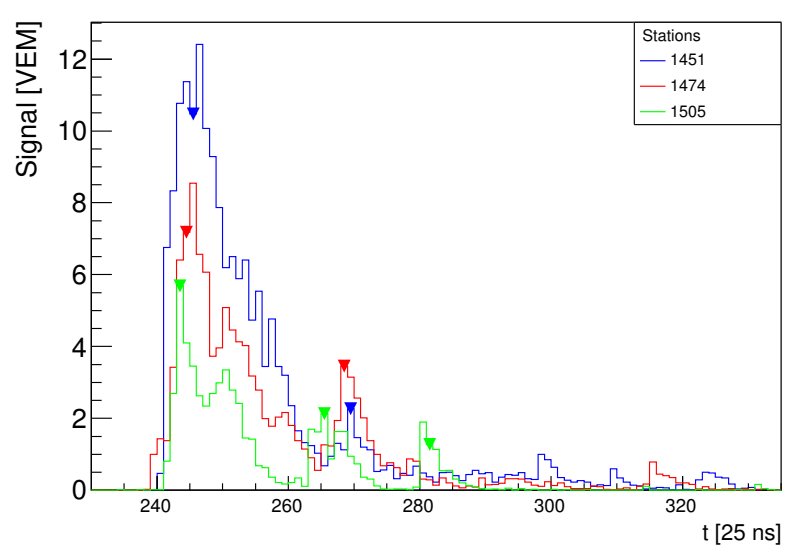

Evento: auger_161802666500__sd_38432843

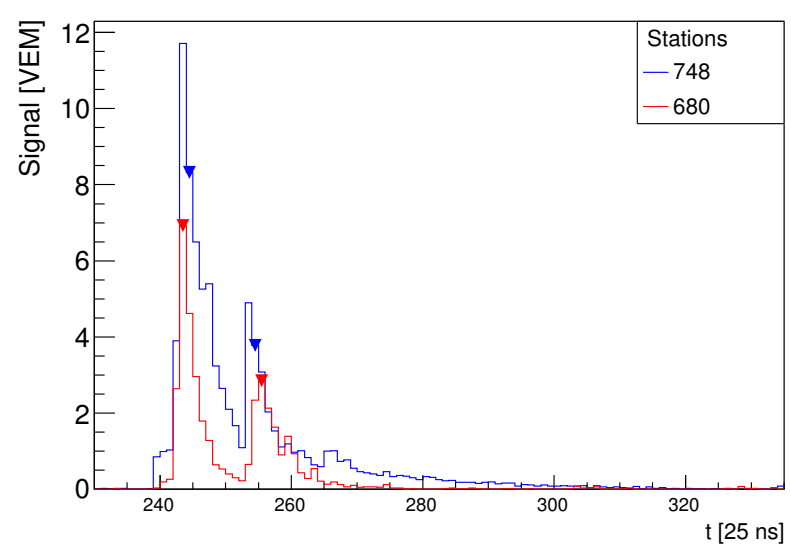

continua 
continuação

Evento: auger_142437413300__sd_28896147

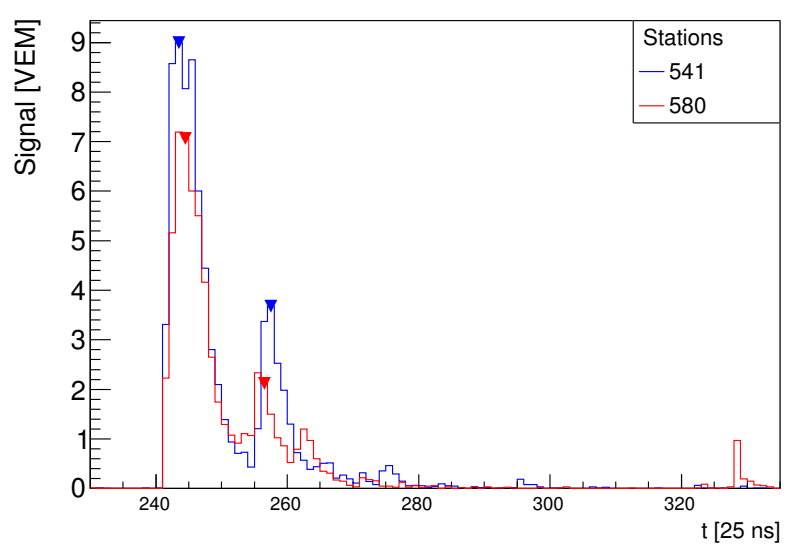

Evento: auger_151578268301__sd_33216769

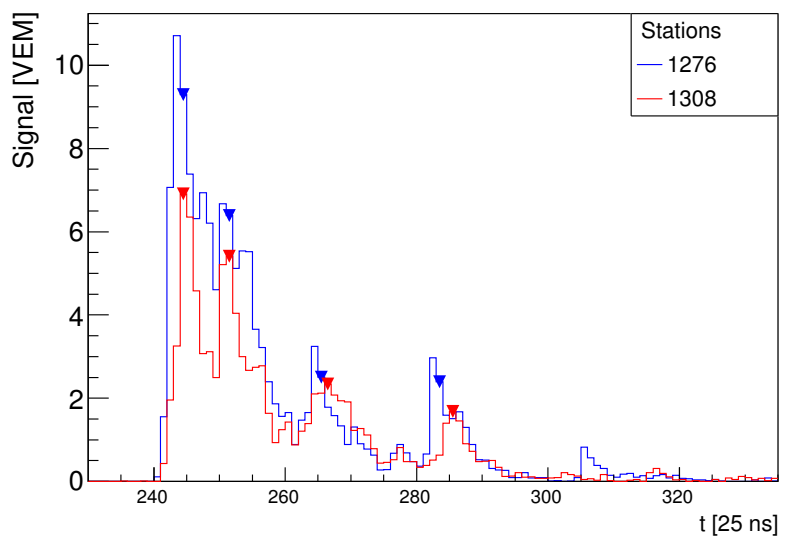

Figura 12 - Exemplo de eventos encontrados pelo algorítimo aplicado.

Fonte: Elaborada pelo autor.

Na Figura 12 cada estação é representada por cores diferentes e cada gráfico mostra o sinal registrado em função do tempo de eventos selecionados pelo filtro aplicado. Os triângulos coloridos indicam a posição dos picos encontrados no espectro usando a função SearchHighRes.

Primeiramente, se nota a variedade de eventos encontrados, uns com duas ou três estações com os sinais correlacionados e outros com 2, 3 ou até 4 picos em cada sequência temporal.

Em segundo, o algoritmo teve grande sucesso em detectar o padrão de sinal procurado. Nas analises realizadas foram estudos os eventos registrados da metade de ano de 2014 ao fim de 2016. Onde encontramos 3228 eventos com as características desejadas, representando $3.78 \%$ do total analisado. 



\section{BUSCA POR PADRÕES EM EVENTOS}

Nesse capítulo será abordada a análise dos dados obtidos na tentativa de caracterizar um padrão buscando semelhanças ou tendências que possibilita diferenciar os eventos anômalos dos eventos comuns, com o objetivo de descobrir a origem desse sinal incomum.

\subsection{Distribuição de Frequência}

Em uma primeira análise dos dados separados, foi montada uma série de histogramas com a finalidade de comparar o comportamento de ambos os grupos de dados, selecionados e não selecionados, de forma separada. Essa separação permite olhar o comportamento desses dois grupos de eventos, buscando por comportamentos que os diferencie. Para fins de comparação, os dados dos dois grupos foram normalizados de forma que a área de cada gráfico seja um.

Os primeiros gráficos, Figura 13, destacam elementos relacionados a alguma característica do chuveiro atmosférico formado pelo raio cósmico primário. Começando pelo fator energia, que representa o logaritmo da energia da partícula primária que gera o chuveiro atmosférico. Em segundo, a variável $S_{1000}$ que representa o valor total do sinal, em VEM, a 1000 metros do eixo do chuveiro, que revela também o tamanho do chuveiro criado. A variável Beta é o primeiro parâmetro de ajuste da Função de Nishimura-Kamata-Greisen ( Equação 2.2) e a variável Gamma é o segundo parâmetro de ajuste da Função de Nishimura-Kamata-Greisen ( Equação 2.2).

Os gráficos seguintes, Figura 14, destacam características relacionadas à direção de chegada do raio cósmico primário. Primeiro são mostradas as coordenadas do Sistema Galáctico, latitude e longitude. Esse é um sistema de coordenadas celestes que tem como plano fundamental o plano do disco da Via-Láctea e usa o Sol como centro de referência. Em seguida, é mostrado o ângulo zenital, que pertence ao Sistema Horizontal de Coordenadas. Nesse sistema é definido o local do observador como o plano fundamental e portanto o Observatório é adotado como origem do sistema.

A Figura 13 e a Figura 14 mostram o comportamento de variáveis dos chuveiros formadas em cada evento comparando a contagem de eventos analisados, em preto, com a contagem de eventos selecionados, em vermelho.

As Figura 13a, Figura 13b, Figura 14a e Figura 14b apresentam o mesmo comportamento em ambos os grupos. No entanto, nada que possa configurar um padrão distinto foi identificado em nenhum dos gráficos. 


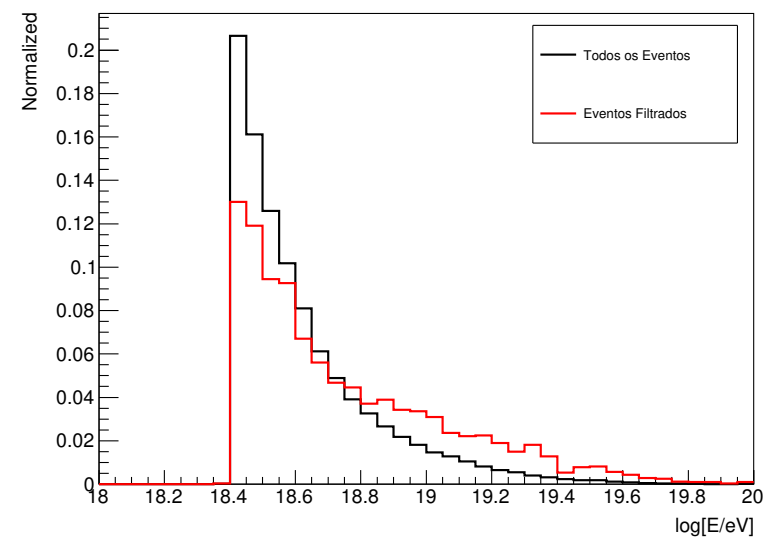

(a) Energia da partícula primária.

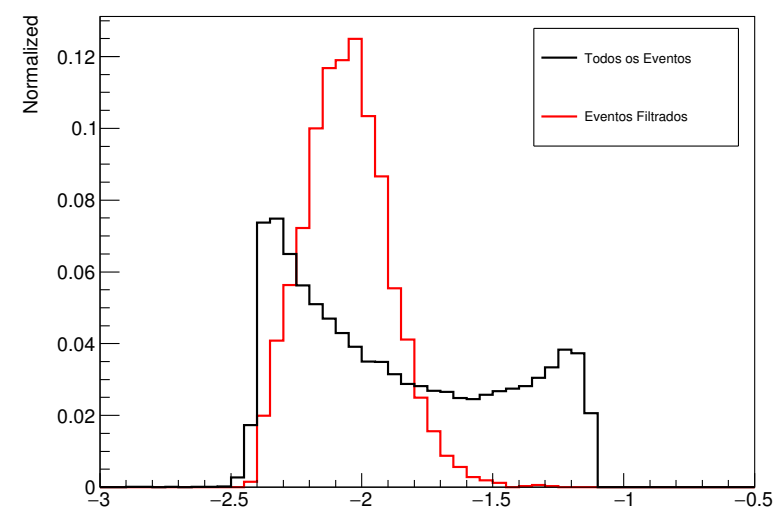

(c) Primeiro parâmetro de ajuste $(\beta)$ da Equa-(d) Segundo parâmetro de ajuste $(\gamma)$ da Equação 2.2 .

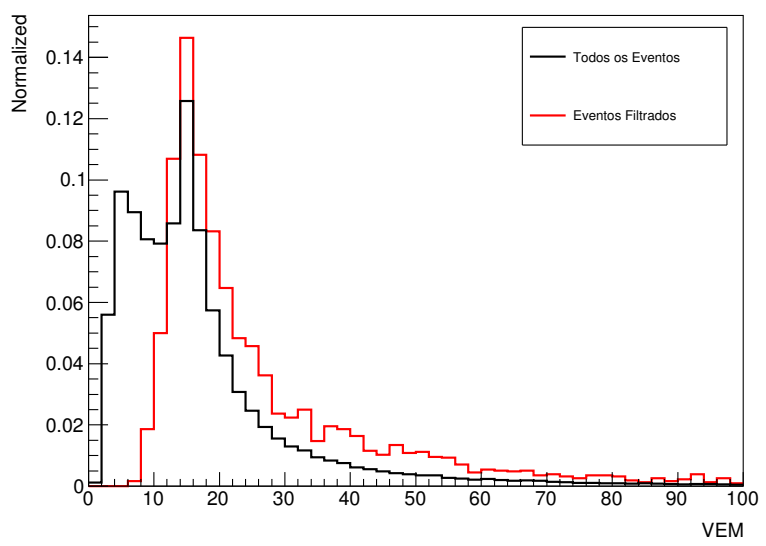

(b) Intensidade total a $1000 \mathrm{~m}$ do eixo.

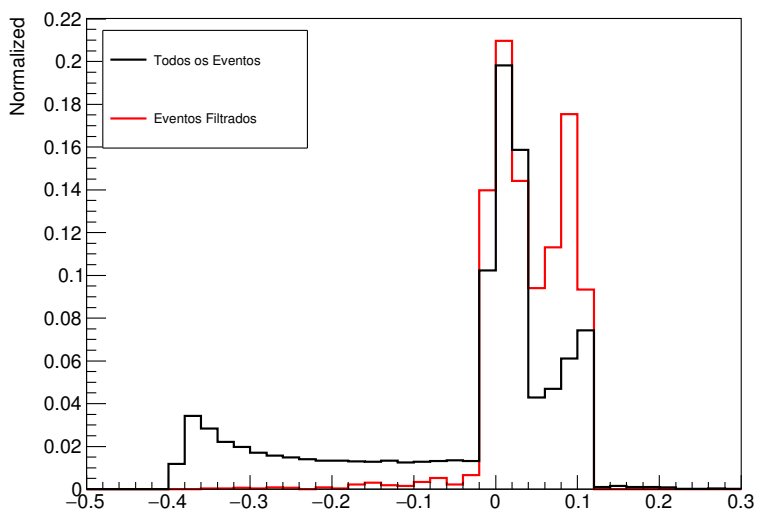

ção 2.2 .

Figura 13 - Histogramas de variáveis relacionadas às caraterísticas de chuveiros atmosféricos detectados pelo observatório.

Fonte: Elaborada pelo autor. 


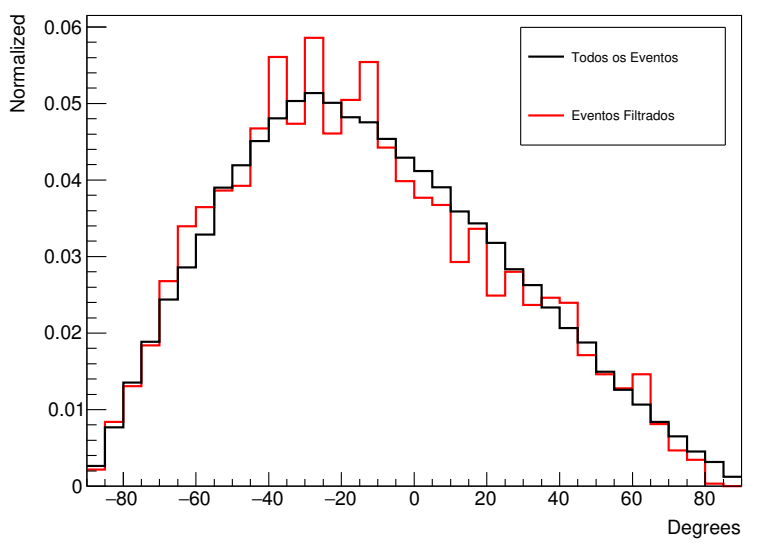

(a) Latitude galáctica.

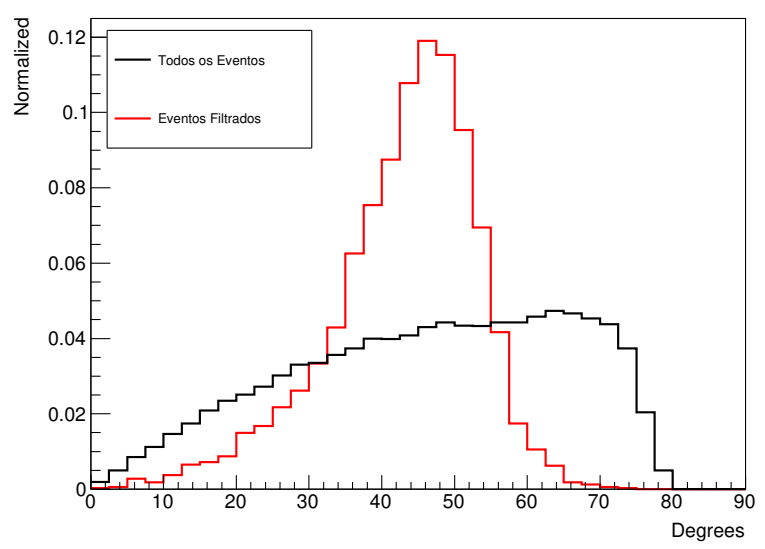

(c) Ângulo zenital, tomando o observatório como centro de referência.

Figura 14 - Histogramas de variáveis de direção dos chuveiros atmosféricos detectados pelo observatório.

Fonte: Elaborada pelo autor.

Nas Figura 13c, Figura 13d e Figura 14c é possível notar um comportamento coletivo distinto de um grupo para o outro com relação a sua forma, entretanto esses comportamentos não são separáveis. Portanto, não podemos prever quando é mais provável que um evento desse ocorra, só olhando para esses gráficos.

\subsection{Análise do Desenvolvimento Longitudinal}

Os telescópios de fluorescência operam apenas durante as noites limpas e sem lua, porém são um método de detecção independente dos detectores Cherenkov. Esses telescópios obtêm informações únicas que são usadas para complementar os dados obtidos pelos detectores no solo. 


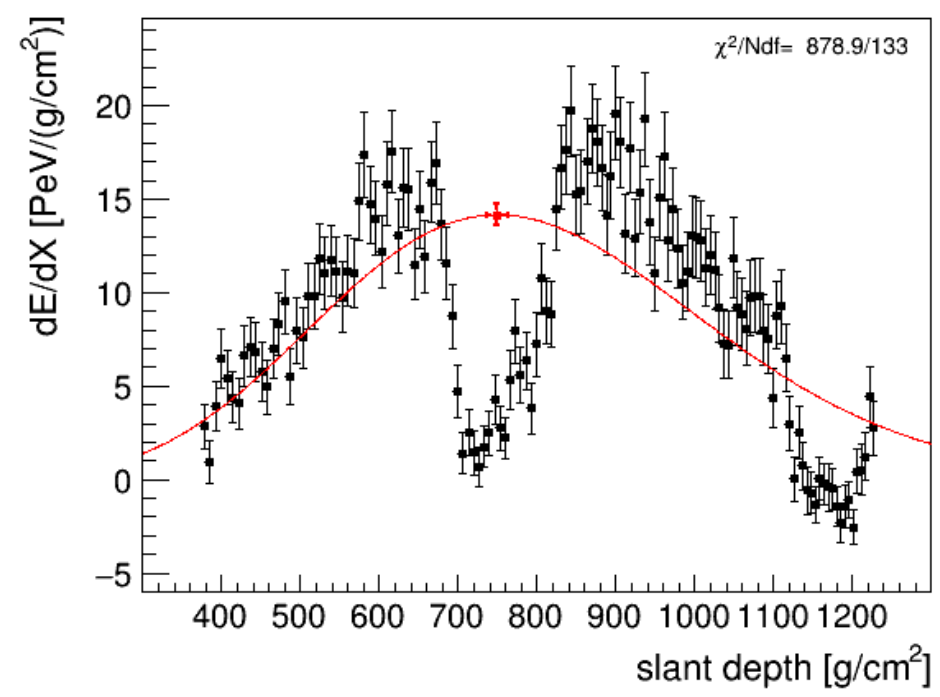

(a)

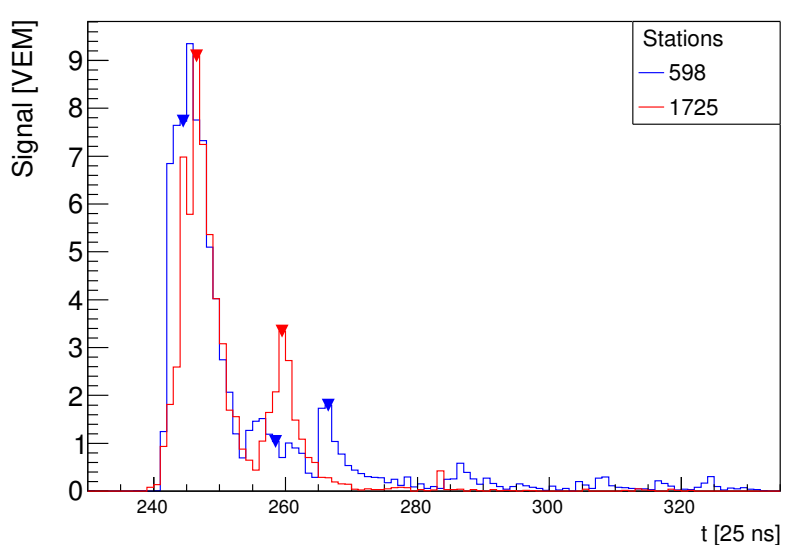

(b)

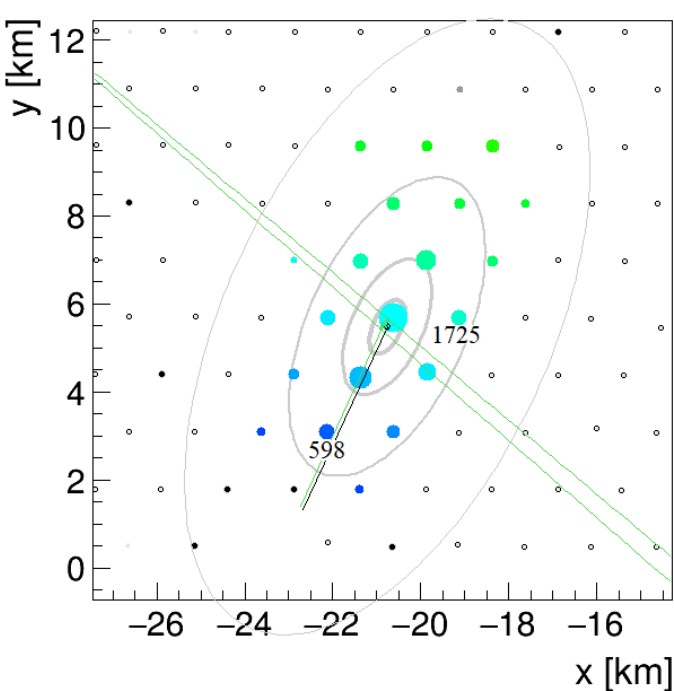

(c)

Figura 15 - Perfil longitudinal (a) de um evento selecionado que apresenta um comportamento incomum, juntamente com a sequência temporal (b) e distribuição dos detectores de solo (c). Evento: auger_120227195300__sd_13621719

Fonte: Elaborada pelo autor.

Numa segunda tentativa de caracterizar um padrão nos dados analisados, estudamos o desenvolvimento longitudinal do chuveiro, ou seja, o número de partículas em função da profundidade na atmosfera. O perfil longitudinal dos chuveiros atmosféricos somente é observado pelos telescópios de fluorescência. Assim, foi necessário utilizar os dados dos eventos híbridos do observatório Auger, chuveiros detectados pelos detectores de superfície e pelos telescópios de fluorescência simultaneamente. 
Os dados utilizados nessa análise foram os eventos detectados no decorrer de dez anos, de 2006 a 2016, um período maior que os analisados antes pelo fato dos eventos híbridos serem mais raros, pois os telescópios FD não operam 24 horas por dia como os detectores SD.

Os telescópios do observatório Auger medem a energia depositada em função da profundidade na atmosfera para cada evento registrado. Normalmente é esperado que esse valor aumente até atingir um máximo e depois volte a diminuir. Mas em alguns dos eventos selecionados anteriormente, um padrão incomum ocorre.

A Figura 15a mostra o perfil longitudinal de um chuveiro que apresenta dois pontos de máximo na atmosfera, como se fosse criado um chuveiro secundário ao longo do seu desenvolvimento.

Essa etapa foi dedicada a verificar se esses fenômenos, os picos extras nas estações SD e o perfil longitudinal incomum, possuem alguma relação. Para tal, foi calculada a diferença de tempo que as partículas produzidas nesses dois pontos de máximo levariam para chegar a uma estação no solo.

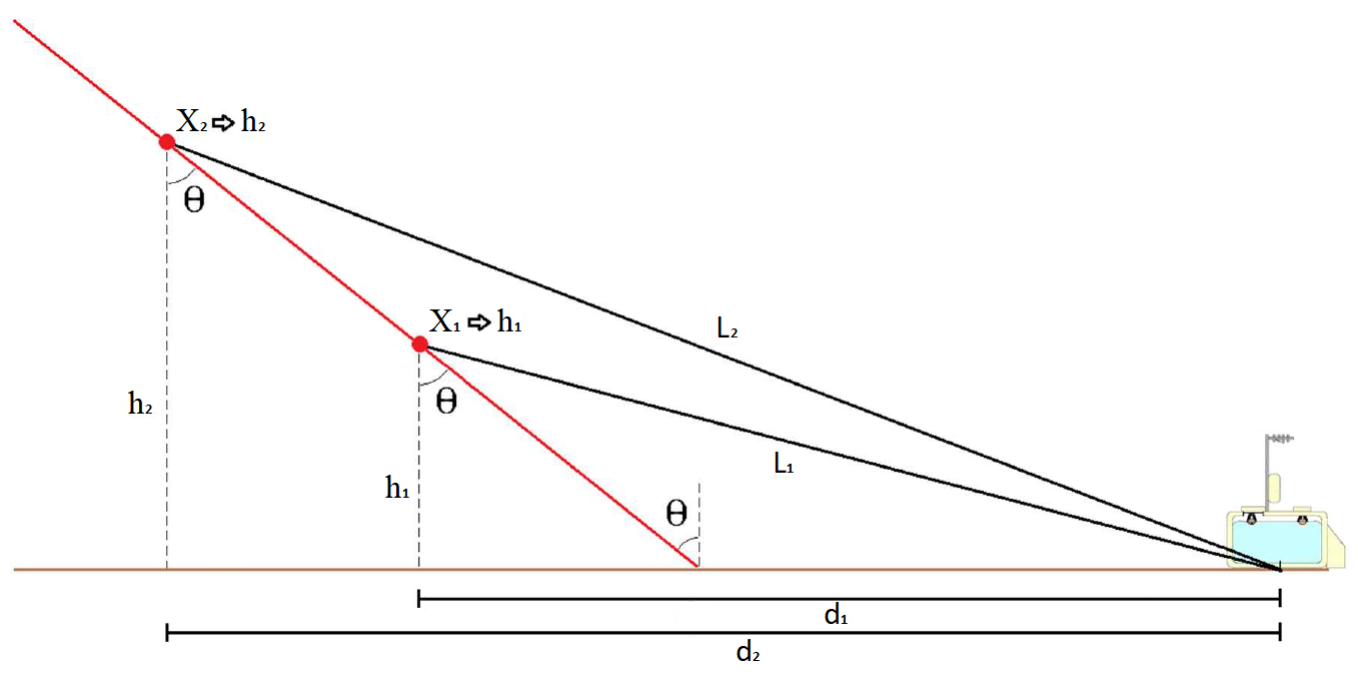

Figura 16 - Geometria do problema, destacando a distância percorrida ente os pontos de máximo de partículas e as estações no solo.

Fonte: Elaborada pelo autor.

A Figura 16 ilustra o problema em questão. Em vermelho, está mostrada a direção de chegada do chuveiro e os pontos marcam as posições em que temos o maior número de partículas na atmosfera, pontos esses que são dados em profundidade na atmosfera $\left(X_{1} \mathrm{e}\right.$ $\left.X_{2}\right)$ mas podem ser convertidos em alturas $\left(h_{1}\right.$ e $\left.h_{2}\right)$. Dentre as informações do evento, temos as posições de cada estação, a posição do centro do chuveiro e o valor do ângulo zenital da chegada do chuveiro. 
A diferença de caminho entre esses dois pontos de máximos até uma estação no solo é dada pela equação:

$$
\Delta L=L_{2}-L_{1}
$$

onde $L_{1}$ e $L_{2}$ são cada uma das distâncias percorridas pelas partículas geradas em cada ponto de máximo.

Por uma geometria simples é possível determinar essas distâncias, com as informações fornecidas pela reconstrução do evento, usando a seguinte equação:

$$
L_{1,2}=\sqrt{h_{1,2}^{2}+d_{1,2}^{2}} .
$$

Assumindo que as partículas estão a uma velocidade próxima à da luz, a diferença de tempo de chegada das partículas será dada por:

$$
\tau=\frac{\Delta L}{c}
$$

Aplicando o método descrito para os eventos em que o perfil longitudinal apresenta esse comportamento incomum, a diferença de tempo encontrada foi da mesma ordem em todos os eventos analisados. O valor obtido foi em torno de 11.000 ns. Agora olhando para o comportamento incomum do sinal nas estações SD encontrados anteriormente, as diferenças de tempo entre os picos nessas estações estão sempre entre 300 e 375 ns.

Comparando esses dois valores percebe-se que eles diferem de mais de uma ordem de grandeza, portanto pode-se concluir que esses fenômenos não estão correlacionados. Em outras palavras, as anomalias na distribuição longitudinal e os sinais incomuns nas estações de solo não são causadas pelo mesmo efeito.

\subsection{Procura por características incomuns em eventos simulados}

A análise subsequente foi testar a hipótese de que a origem do sinal incomum possa estar, de alguma forma, relacionada à resposta dos detectores, ou em alguma etapa da reconstrução do evento.

Para isso foram escolhidos alguns dos eventos observados anteriormente para serem simulados. Cada evento escolhido foi simulado da ordem de 1000 vezes. Essas simulações foram realizadas utilizando o CORSIKA (41), que é um programa que utiliza simulações de Monte Carlo (42) para estudar a evolução de chuveiros atmosféricos extensos na atmosfera, onde diversas partículas podem ser introduzidas como primários. Para efetua-las foi empregado os recursos do supercomputador Sdumont (<http://sdumont.lncc.br $>$ ). 
Em seguida, esses eventos foram reconstituídos utilizando os módulos do Offline (43), um conjunto de ferramentas computacionais, com o propósito de simular uma resposta dos detectores do observatório para um dado chuveiro atmosférico escolhido, nesse caso para os detectores de superfície.

\section{Primeiro Evento}

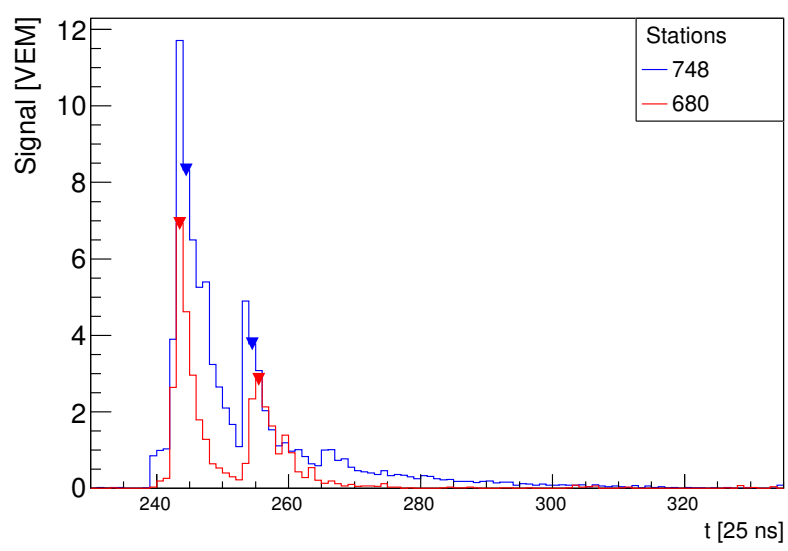

Segundo Evento

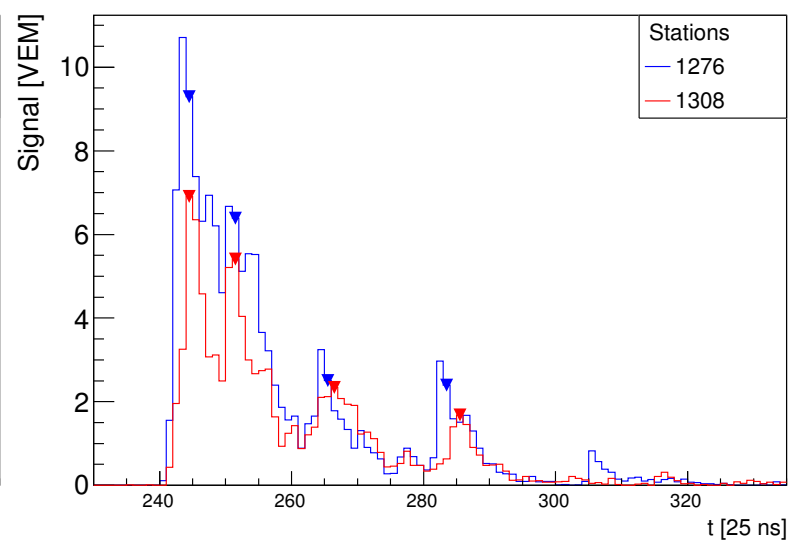

Evento: auger_151578268301__sd_33216769

Energia: $1.09 \times 10^{19} \mathrm{eV}$

Ângulo zenital: $51^{\circ}$
Evento: auger_161802666500
Energia: $6.01 \times 10^{18} \mathrm{eV}$

Ângulo zenital: $49^{\circ}$ sd_38432843

(2)


A Figura 17 mostra o sinal registrado dos três eventos escolhidos para serem simulados, destacando sua energia e o ângulo zenital de cada chuveiro. Em cada conjunto de eventos simulados, foi procurado pelos eventos que apresentam o padrão desejado, utilizando o mesmo algoritmo usado para analisar os eventos reais.

A Figura 18 mostra uma tabela com os resultados obtidos com essas simulações.

\begin{tabular}{|c|c|c|c|}
\hline Evento & Primário & $\begin{array}{c}\text { Número de Eventos } \\
\text { analisados }\end{array}$ & $\begin{array}{c}\text { Número de Eventos } \\
\text { selecionados (proporção) }\end{array}$ \\
\hline \multirow{2}{*}{ Primeiro } & Próton & 995 & $67(6.73 \%)$ \\
\hline \multirow{2}{*}{ Segundo } & Ferro & 761 & $68(9.93 \%)$ \\
\hline & Próton & 1001 & $325(32.46 \%)$ \\
\hline Terceiro & Ferro & 763 & $228(29.88 \%)$ \\
\hline
\end{tabular}

Figura 18 - Resumo dos resultados obtidos nas simulações de chuveiros atmosféricos.

Fonte: Elaborada pelo autor.

Na primeira coluna, temos qual o evento simulado. Na segunda, qual partícula foi introduzida como primário no código de simulação. Em "Número de Eventos Analisados", é mostrado o número de eventos reconstituídos com sucesso e que puderam ser analisados. Em "Número de Eventos Selecionados", é dada a quantidade de eventos que apresenta o comportamento de interesse nesse trabalho, mostrando entre parentes a porcentagem deles com relação ao número total de eventos analisados.

Os resultados mostram que as características de interesse aparecem em eventos simulados no observatório para os dois tipos de primários utilizados e nas três diferentes energias escolhidas, com uma frequência maior que a média nos eventos reais. Os resultados revelam que o efeito que causa esse comportamento independe do tipo de primário que gera o chuveiro e que esse efeito já é algo previsto em simulações.

\subsection{Proporção de eventos selecionados frente ao total de eventos analisados}

Em última análise, nesse trabalho, foi avaliada a proporção de eventos com o sinal com o padrão em estudo, e comparada com o total de eventos analisados em função da energia, tanto para os eventos reais como para os eventos simulados. O objetivo dessa comparação é determinar se o fenômeno que provoca esse tipo de evento está presente nos eventos simulados na mesma frequência que nos eventos reais. 


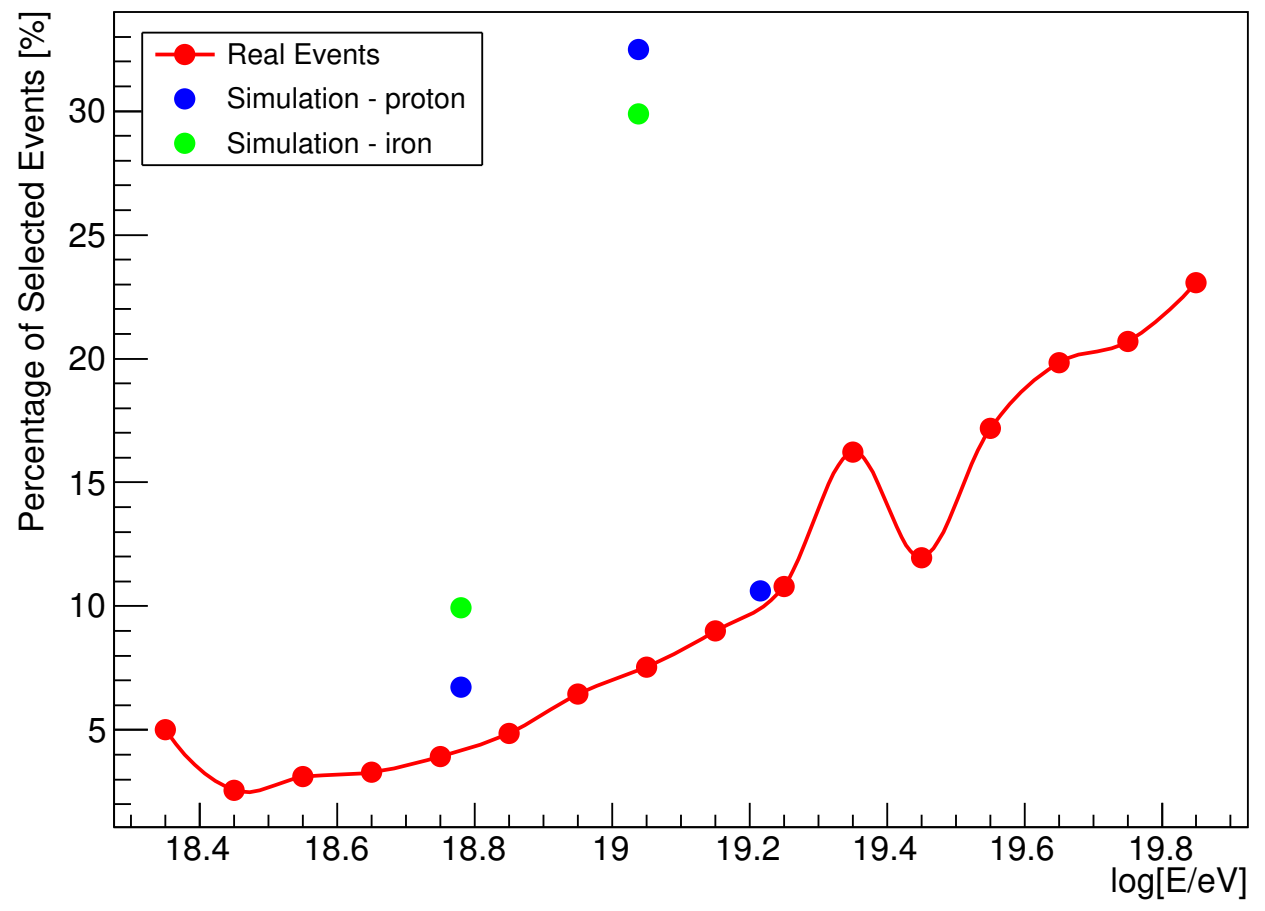

Figura 19 - Porcentagem de eventos selecionados em função da energia.

Fonte: Elaborada pelo autor.

A Figura 19 mostra os resultados obtidos nas simulações comparando com os números dos eventos reais analisados anteriormente.

Os pontos no gráfico mostram a razão número de eventos que apresenta o padrão em estudo pelo número total de eventos em função da energia do primário do chuveiro em três situações. Em vermelho, os eventos reais, em azul os eventos simulados utilizando um próton como partícula primária e em verde os eventos simulados utilizando um núcleo de ferro como partícula primária.

Com base nas informações do gráfico, quanto maior a energia inicial do chuveiro maior é a probabilidade de se encontrar um evento com o sinal característico de mais de um pico, coincidindo em pelo menos duas estações, tanto em eventos reais quanto em eventos simulados.

A proporção de eventos incomuns nos eventos simulados é maior que nos eventos reais, nos casos analisados. Isso sugere que não se trata de um fenômeno novo, pois esse comportamento já é previsto em simulações. Mesmo assim, o fator de sua ocorrência permanece desconhecido. 



\section{CONCLUSÃO}

Esse trabalho foi dedicado a uma análise da evolução temporal do sinal dos detectores de superfície de um conjunto específico de eventos registrado pelo Observatório Pierre Auger, com a finalidade de entender a origem de seu comportamento. Esse capítulo é dedicado a uma síntese dos resultados obtidos através das análises feitas.

Após a separação dos dados pelo algoritmo aplicado, foi criada uma série de histogramas com o propósito de olhar as características do chuveiro em cada evento. Dessa forma, tentou-se identificar um comportamento singular nos sinais escolhidos, possibilitando prever a ocorrência deles em eventos futuros.

Esses resultados foram apresentados na seção 5.1, onde em sete gráficos de distribuição de frequência é comparado o número de eventos selecionados com o total de eventos analisados, cada um para uma característica distinta do chuveiro gerado. Porém, em nenhum desses gráficos é possível diferenciar um comportamento dos eventos selecionados distinto do conjunto total de eventos analisados. Esse resultado indica que o fator responsável por criar essas subestruturas na frente de partículas não está atrelado a nenhuma característica física de um dado evento.

Como resultado, se conclui que não podemos prever a ocorrência de tais eventos baseando-nos apenas nas características dos chuveiros atmosféricos medidos. Isso sugere que qualquer chuveiro formado na atmosfera tem potencial para apresentar uma sequência temporal com as características incomuns que são o alvo desse estudo.

Uma segunda análise, olhando apenas para eventos híbridos, foi inspirada em verificar o comportamento do desenvolvimento longitudinal do chuveiro e então comparar com o sinal medido pelos detectores de solo. Essa ideia surgiu com o intuito de testar uma possível relação entre o aparecimento de subestruturas na frente de partículas e o comportamento incomum no desenvolvimento do chuveiro, observado em certos eventos selecionados anteriormente, em que se notou que em alguns desses perfis havia um segundo ponto ao longo do eixo do chuveiro em que o número de partículas geradas atingem um máximo.

O estudo realizado no perfil longitudinal mostrou que a diferença de tempo em que ocorrem os picos encontrados nos sinais dos detectores SD e o tempo que as partículas levam para percorrer a distância entre os dois pontos de máximo, ao longo do seu desenvolvimento, possuem mais de uma ordem de grandeza de diferença. Essa distinção nos valores temporais entre os dois casos evidencia que esses fenômenos não estão correlacionados.

Os resultados encontrados sugerem que esse comportamento é descrito por outro tipo de sinal anômalo, não previsto e que não possui relação com o objeto de estudo desse 
trabalho e portanto deve ser analisado separadamente.

Continuando na tentativa de entender melhor a origem desse fenômeno, na seção 5.3 foram escolhidos alguns dos eventos selecionados anteriormente para serem simulados, tanto o chuveiro de partículas quanto a detecção no observatório. O objetivo nessa etapa foi utilizar simulações de Monte Carlo dos chuveiros e detectores para quantificar o aparecimento dessas subestruturas.

Os resultados obtidos nessa avaliação, mostrados na tabela da Figura 18, revelaram que as características procuradas nos eventos reais aparecem, sim, em eventos simulados, independentemente do tipo do primário utilizado. Outro ponto notado foi o fato de a frequência desse tipo de evento ser maior nas simulações, mostrando que, mesmo não sabendo qual o fenômeno que causa esse comportamento, sabe-se que ele é reproduzido em simulação de chuveiros.

Para finalizar as análises, na seção 5.4, foi comparado o número de eventos selecionados com o número total de eventos analisados tanto para os dados reais quanto para os eventos simulados.

Essa comparação foi realizada por meio do gráfico na Figura 19, que, por sua vez, mostra que a probabilidade de um evento possuir pelo menos duas estruturas temporais, coincidentes em mais um detector de solo depende da energia desse evento. Sendo mais comum em chuveiros mais energéticos.

Outra tendência evidente é o fato de a razão entre o número de eventos selecionados e o de eventos analisados ser sempre superior nos eventos simulados em comparação aos reais.

Após os estudos realizados, foi notado que esse fenômeno não é tão incomum como suposto inicialmente, chegando a uma probabilidade de ocorrência superior a $20 \%$ nos eventos mais energéticos detectados pelo observatório. Seja qual for o fenômeno, ele está previsto nas simulações sendo algo natural que não pôde ser determinado nas análises feitas nesse trabalho. 


\section{REFERÊNCIAS}

1 BUSTAMANTE, M. C. A descoberta dos raios cósmicos ou o problema da ionização do ar atmosférico. Revista Brasileira de Ensino de Física, v. 35, n. 2, 2013. doi: 10.1590/s1806-11172013000200030.

2 HESS, V. F. Über beobachtungen der durchdringenden Strahlung bei sieben Freiballonfahrten. Physikalische Zeitschrift, v. 13, p. 1084-1091, 1912.

3 NEDDERNEYER, S. H.; ANDERSON, C. Note on the nature of cosmic-ray particles. Physical Review, v. 51, n. 10, p. 884-886, 1937. doi: 10.1103/physrev.51.884.

4 AUGER, P. et al. Extensive cosmic-ray showers. Reviews of Modern Physics, v. 11, n. 3-4, p. 288-291, 1939. doi: 10.1103/RevModPhys.11.288.

5 LINSLEY, J. Evidence for a primary cosmic-ray particle with energy $10^{20} \mathrm{eV}$. Physical Review Letters, v. 10, n. 4, p. 146-148, 1963. doi: 10.1103/physrevlett.10.146.

6 GREISEN, K. End to the cosmic-ray spectrum? Physical Review Letters, v. 16, n. 17, p. 748-750, 1966. doi: 10.1103/PhysRevLett.16.748.

7 ZATSEPIN, G. T.; KUZMIN, V. A. Upper limit of the spectrum of cosmic rays. Soviet Journal of Experimental and Theoretical Physics Letters, v. 4, n. 4, p. 78-80, 1966.

8 OLINTO, A. V. Ultra high energy cosmic rays: the theoretical challenge. Physics Reports, v. 333-334, p. 329-348, 2000. doi: 10.1016/S0370-1573(00)00028-4.

9 FERMI, E. On the origin of the cosmic radiation. Physical Review, v. 75, n. 8, p. 1169-1174, 1949. doi: 10.1103/physrev.75.1169.

10 HILLAS, A. M. The origin of ultra-high-energy cosmic rays. Annual Review of Astronomy and Astrophysics, v. 22, n. 1, p. 425-444, 1984. doi: 10.1146/annurev.aa.22.090184.002233.

11 ENGEL, R. et al. Extensive air showers and hadronic interactions at high energy. Annual Review of Nuclear and Particle Science, v. 61, n. 1, p. 467-489, 2011. doi: 10.1146/annurev.nucl.012809.104544.

12 MILLIS, J. P. Cosmic rays: the fastest travelers in the universe. ThoughtCo. Jan. 5, 2018. Disponível em: <https://www.thoughtco.com/ history-and-sources-of-cosmic-rays-3073300>. Acesso em: 01 nov. 2017.

13 BIERMANN, P. L.; SOUZA, V. de. Centaurus A: the extragalactic source of cosmic rays with energies above the knee. The Astrophysical Journal, v. 746, n. 1, p. 72, 2012. doi: 10.1088/0004-637x/746/1/72.

14 KAMPERT, K.-H.; WATSON, A. A. Extensive air showers and ultra high-energy cosmic rays: a historical review. The European Physical Journal H, v. 37, n. 3, p. 359-412, July 2012. doi: 10.1140/epjh/e2012-30013-x. 
15 KOTERA, K.; OLINTO, A. V. The astrophysics of ultrahigh-energy cosmic rays. Annual Review of Astronomy and Astrophysics, v. 49, n. 1, p. 119-153, 2011. doi: 10.1146/annurev-astro-081710-102620.

16 TORRES, D. F.; ANCHORDOQUI, L. A. Astrophysical origins of ultrahigh energy cosmic rays. Reports on Progress in Physics, v. 67, n. 9, p. 1663-1730, 2004. doi: 10.1088/0034-4885/67/9/r03.

17 MOLLERACH, S.; ROULET, E. Progress in high-energy cosmic ray physics. Progress in Particle and Nuclear Physics, Elsevier, v. 98, p. 85-118, 2017. doi: 10.1016/j.ppnp.2017.10.002.

18 STANEV, T. High energy cosmic rays. 2nd. ed. Dordrecht: Springer, 2010. 333 p.

19 GAISSER, T. K.; HILLAS, A. M. Reliability of the method of constant intensity cuts for reconstructing the average development of vertical showers. In: INTERNATIONAL COSMIC RAY CONFERENCE, 15., 1977. Proceedings... Plovdiv, Bulgaria: ICRC, 1977. p. 353-357.

20 KAMATA, K.; NISHIMURA, J. The lateral and the angular structure functions of electron showers. Progress of Theoretical Physics Supplement, v. 6, p. 93-155, 1958. doi: 10.1143/PTPS.6.93.

21 HARNETT, E. Cosmic rays: earth and space sciences. [s.n.]. Disponível em: $<$ http://faculty.washington.edu/mccarthy/ESS472/lectures/lec13_ESS472.pdf>. Acesso em: 11 set. 2017.

22 FRACCHIOLLA, C. Estudo da resolução angular do Observatório Pierre Auger. 2007. 68 f. Dissertação (Mestrado em Física) - Departamento de Física, Pontifícia Universidade Católica, Rio de Janeiro, 2007.

23 ANCHORDOQUI, L. et al. High energy physics in the atmosphere: phenomenology of cosmic ray air showers. Annals of Physics, v. 314, p. 145-207, 2004. doi: 10.1016/j.aop.2004.07.003.

24 AUGER COLLABORATION et al. Properties and performance of the prototype instrument for the pierre auger observatory. Nuclear Instruments and Methods in Physics Research Section A, v. 523, p. 50-94, 2004. doi: 10.1016/j.nima.2003.12.012.

25 THE PIERRE AUGER COLLABORATION. The Pierre Auger cosmic ray observatory. Nuclear Instruments and Methods in Physics Research A, v. 798, p. 172-213, 2015. doi: 10.1016/j.nima.2015.06.058.

26 Spectral calibration of the fluorescence telescopes of the Pierre Auger Observatory. Astroparticle Physics, v. 95, p. 44-56, 2017. doi: 10.1016/j.astropartphys.2017.09.001.

27 AUGER COLlabORATION. Auger country. Disponível em: < https: //www.auger.org/images/Collaboration/auger-country_2015-april.png>. Acesso em: 30 nov. 2017.

28 SHELLARD, R. C. First results from the Pierre Auger Observatory. Brazilian Journal of Physics, v. 35, n. 4, 2006. doi: 10.1590/S0103-97332006000700012. 
29 THOMSON, M. Modern particle physics. New York: Cambridge University Press, 2013. 570 p.

30 ARGIRÒ, S. et al. The offline software framework of the Pierre Auger Observatory. Nuclear Instruments and Methods in Physics Research Section A, v. 580, n. 3, p. 1485-1496, 2007. doi: 10.1016/j.nima.2007.07.010.

31 ALLEN, J. et al. The Pierre Auger Observatory offline software. Journal of Physics, v. 119, n. 3, 2008. doi: 10.1088/1742-6596/119/3/032002.

32 VALIÑO, I. The flux of ultra-high energy cosmic rays after 10 years of operation of the Pierre Auger Observatory. In: INTERNATIONAL COSMIC RAY CONFERENCE, 34., 2015. Proceedings... The Hague, The Netherlands: ICRC, 2015.

33 THE PIERRE AUGER COLLABORATION. Observation of a large-scale anisotropy in the arrival directions of cosmic rays above $8 \times 10^{18} \mathrm{eV}$. Science, v. 357, n. 6357, p. 1266-1270, 2017. doi: 10.1126/science.aan4338.

34 BOHÁČOVÁ, M. Highlights from the Pierre Auger Observatory. Nuclear and Particle Physics Proceedings, v. 291-293, p. 82-89, 2017. doi: 10.1016/j.nuclphysbps.2017.06.017.

35 THE PIERRE AUGER COLLABORATION. Searches for large-scale anisotropy in the arrival directions of cosmic rays detected above energy of $10^{19} \mathrm{eV}$ at the Pierre Auger Observatory and the Telescope Array. The Astrophysical Journal, v. 794, n. 2, p. 172, 2014. doi: $10.1088 / 0004-637 x / 794 / 2 / 172$.

36 Improved limit to the diffuse flux of ultrahigh energy neutrinos from the Pierre Auger Observatory. Physical Review D, v. 91, n. 9, 2015. doi: 10.1103/physrevd.91.092008.

37 Measurement of the proton-air cross-section at $\sqrt{s}=57 \mathrm{TeV}$ with the Pierre Auger Observatory. Physical Review Letters, v. 109, n. 6, 2012. doi: 10.1103/physrevlett.109.062002.

38 Muons in air showers at the Pierre Auger Observatory: mean number in highly inclined events. Physical Review D, v. 91, n. 3, 2015. doi: 10.1103/physrevd.91.032003.

39 BRUN, R.; RADEMAKERS, F. ROOT - an object oriented data analysis framework. Nuclear Instruments and Methods in Physics Research Section A, v. 389, n. 1-2, p. 81-86, 1997. doi: 10.1016/S0168-9002(97)00048-X.

40 MARISCOTTI, M. A. A method for automatic identification of peaks in the presence of background and its application to spectrum analysis. Nuclear Instruments and Methods, v. 50, n. 2, p. 309-320, 1967. doi: 10.1016/0029-554X(67)90058-4.

41 HECK, D. et al. CORSIKA: a Monte Carlo code to simulate extensive air showers. Karlsruhe, Germany: Forschungszentrum Karlsruhe, 1998.

42 MOONEY, C. Z. Monte Carlo simulation. Thousand Oaks: Sage Publications, 2005. v. 116. 
43 VEBERIč, D.; ROTH, M. SD Reconstruction. Pierre Auger Observatory, 2009. 34 p. Offline reference manual. Disponível em: < https://augerlal.lal.in2p3.fr/pmwiki/ uploads/SdReconstruction.pdf $>$. Acesso em: 23 jan. 2018. 